\title{
Link Budget Analysis in Designing a Web-application Tool for Military X-Band Satellite Communication
}

\author{
M. Akhtaruzzaman ${ }^{1 *}$, S. M. Sadakatul Bari², Syed Akhter Hossain³, and Md. Mahbubur Rahman4 \\ ${ }^{1}$ R\&D (Robotics) Section, DREAM Robotics Ltd., Dhaka, Bangladesh \\ 2Department of Computer Science and Engineering, Bangladesh Army University of Science and Technology, Saidpur, Bangladesh \\ 3Department of Computer Science and Engineering, Daffodil International University, Dhaka, Bangladesh \\ ${ }^{4}$ Department of Computer Science and Engineering, Military Institute of Science and Technology, Dhaka, Bangladesh \\ emails: ${ }^{* 1}$ akhter900@gmail.com; ${ }^{2}$ sadakatul@baust.edu.bd; ${ }^{3}$ aktarhossain@daffodilvarsity.edu.bd; and ${ }^{4}$ mahbub@cse.mist.ac.bd
}

\section{ART ICLE IN F O}

Article History:

Received: $14^{\text {th }}$ March 2020

Revised: 06 $6^{\text {th }}$ May 2020

Accepted: 09th May 2020

Published online: 21 st July 2020

Keywords:

Link Budget

Military X-Band

Satellite communication

Web calculator

Link budget calculator

\begin{abstract}
A B S T RACT
In satellite communication, Link Budget analysis is the most important part to determine gains and losses of signals from the transmitter to the receiver. Most importantly, it investigates system performance and optimum power which must be received at the receiver channel. In some cases, this information could be generated, saved for past data analysis, and share with peer users which are not found in existing web tools. Thus, it is obvious to design a new Link Budget calculator with users, database, and data retrieval support. This work focuses on designing a Link Budget web tool for X-band satellite communication through literature study and comparative analysis. The X-Band calculator is designed based on HTML, PHP, Javascript, and MySQL by ensuring several security issues, and can be accessed through mobile devices. This paper also focuses on the necessary equations of Link Budget for Uplink (Tx); Satellite; Downlink $(\boldsymbol{R} \boldsymbol{x})$; Azimuth, Elevation, Distance analysis; and Rain attenuation. Though, comparative assessments among various web tools show some fluctuations, overall outputs show satisfactory results with small \% of Errors (PoE) ensuring reliability and viability of the proposed X-Band tool for practical use.
\end{abstract}

(c) 2020 MIJST, All rights reserved.

\section{INTRODUCTION}

The development of satellite technology and its applications are increasing continuously. X-band, known as Super High Frequency (SHF) Satellite Communication, is widely used for military applications while beyond line-of-sight communications are required. The wavelength range of SHF is $10 \mathrm{~cm}$ to $01 \mathrm{~cm}$ where frequency shows an increasing range from $03 \mathrm{GHz}$ to $30 \mathrm{GHz}$. Satellite frequency is considered in between the range of $01-40 \mathrm{GHz}$ where Lband (uses: GPS, satellite mobile, etc.) range is $01-$ $02 \mathrm{GHz}, \mathrm{S}$-band (uses: surface ship radar) range is $02-$ $04 \mathrm{GHz}$, C-band (uses: satellite communication, TV networks, etc.) range is $04-08 \mathrm{GHz}$. X-band is primarily used by the military such as Radar application, short-range tracking, weather monitoring, missile guidance, air traffic control, mapping marine radar, battlefield surveillance, airborne intercept, weapon location, vehicle speed detection for law enforcement (Cole, 2010; Nuroddin et al., 2013; Griffiths et al., 2015). The range of X-band frequency is $08-12 \mathrm{GHz}$ (data rates: $\sim 100 \mathrm{Mbit} \times \mathrm{s}^{-1}$ ). Other bands are Ku-band (range: $12-18 \mathrm{GHz}$; usage: satellite communication), K-band (range: $18-26 \mathrm{GHz}$ ), and Ka- band (range: $26-40 \mathrm{GHz}$; data rates: $>150 \mathrm{Mbit}^{-1} \mathrm{~s}^{-1}$, uses: close-range targeting radars on military aircraft) (Griffiths et al., 2015).

Rapid access to information (RAtI) service has become a global need that can be supported through a wireless communication system. For the military state communication, RAtI is obvious which employs link budget calculations. This paper presents a link budget calculation tool to quantify link performance for military X-band satellite communication. According to the literature study, most of the tools developed so far are for research and study purpose and most of the tools need a special setup (MATLAB, VB, or Spreadsheet). Moreover, available tools are not capable to present necessary calculations in a single window, provide user support, save and retrieval facilities. As a solution to these issues, this study presents the design of a new web application tool for link budget quantification.

\section{BACKGROUND STUDY}

According to the recommendation of International Telecommunication Union (ITU) (ITU-R SA.1024), three primary bands are available at Earth Exploration-Satellite 
Service (EESS) for direct data transmission, which are, Sband $(2.200-2.290 \mathrm{GHz}), \mathrm{X}$-band $(8.025-8.400 \mathrm{GHz})$ and Ka-band $(25.500-27.000 \mathrm{GHz})$ (ITU, 2011). EESS mainly operates in NGSO (Non-geostationary Satellite Orbit) which includes Medium Earth Orbit (MEO) (altitude: $\sim 8000$ to $\sim 20000 \mathrm{~km}$ ) and Low Earth Orbit (LEO) (altitude: $\sim 400$ to $\sim 2000 \mathrm{~km}$ ). Transmission delay for Geo Stationary Orbit (GEO) Satellite is much higher $(\sim 500 \mathrm{~ms})$ comparing to EESS ( 10 ms) (Nizam, 2008; ITU, 2011; Karim, et al., 2018).

Recent research focuses on various kinds of satellites in terms of size, power, and mass, such as small-satellite $(\sim 500 \mathrm{~kg})$, mini-satellite $(500-100 \mathrm{~kg})$, micro-satellite $(100-10 \mathrm{~kg})$, nano-satellite $(10-1 \mathrm{~kg})$, and Femto- \& Pico-satellite $(<1 \mathrm{~kg})$ (Mir, et al., 2018). Several types of data are transmitted in a satellite network, which are text, voice, image, and video streaming. Link budget analysis is necessary for any kind of satellite to identify optimal parameters for link establishment as there are several gains and losses in transmitting data through free space and atmosphere. Some losses are constant, some losses depend on statistical data, and some losses vary because of weather conditions smog, snow, clouds, and specially rainfall (Mahmud \& Khan, 2009; Capela, 2012; Nuroddin et al., 2013; and Mir, et al., 2018). Classification of the main losses of satellite communication can be shown in Figure 1. Link budget presents some pre-calculations to predict performances prior to establishing links between satellite and earth station. Link budget presents acceptable links through comparisons among possible links.

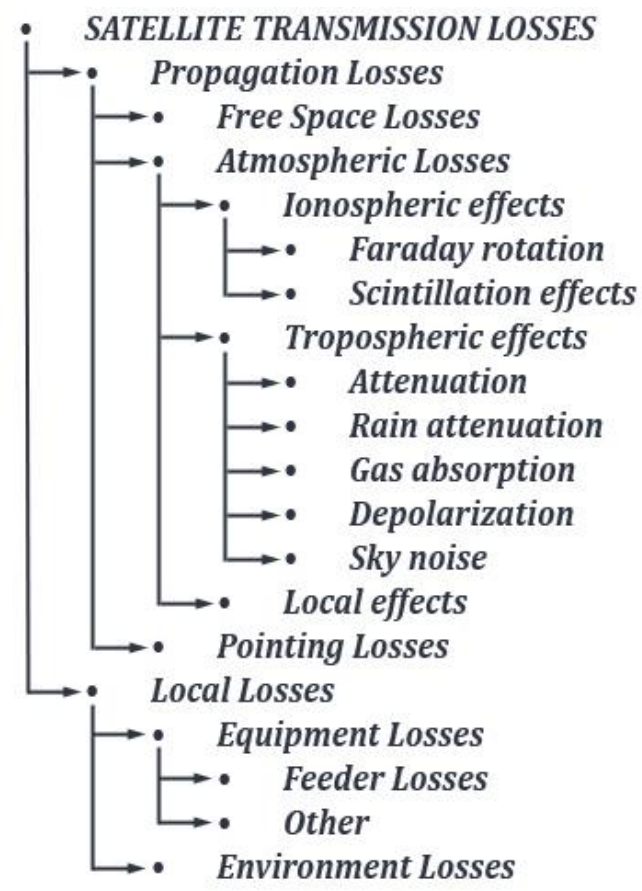

Figure 1: Classification of main losses of satellite communication (Capela, 2012; Zhiger, 2017; Ismail et al., 2017)

MATLAB based link budget calculator is presented in a recent research by Ya'acob et al. (2018) to calculate all the gains and losses of the telecommunication system from a transmitter to receiver through the used medium. This calculator is able to calculate several parameters such as Effective Isotropic Radiated Power (EIRP), effective aperture, path loss, free space path loss, physical aperture, flux density, transmit gain, transmit power, receive gain, receive power, noise temperature ratio, noise density ratio, etc. Another study on developing software tool was conducted for the configuration and calculation of link budget to broadcast multimedia services for GEO Satellite in Ka-band (Mebrek et al., 2012). This software tool was designed and developed based on MATLAB 7.8 by focusing mainly on four separate modules, Uplink, Downlink, Depointing angle, and De-pointing losses, with some other related calculation facilities. A study conducted by AlDalowi, Khoshnaw, and QasMarrogy (2017) presented another MATLAB based tool to calculate net power transmitted by the earth station where losses and attenuation were considered in the link budget calculation. The study also focused on the factors that affect the receiver signals, signal gains and losses. The MATLAB based tool is designed to get all the necessary calculated parameters in a single screen. Visual Basic (VB) programming language was used in another software development project by Yulianto (2012) where a link budget calculator was introduced which includes calculation of Receiver Signal Level (RSL), Free Space Loss (FSL), Cable Loss, EIRP, Fresnel Zone Clearance (FZC), and System Operating Margin (SOM).

The main process of transmitting a signal from earth station to satellite can be described as: signal modulation (changing the form of a signal), converting the band (L-band to C, X, or $\mathrm{Ku}$-band), amplifying signals (increasing amplitude and power), directing the signals to the satellite by using reflector antenna providing extra gain comparing with the isotropic radiation (power flux density), and the signal radiates in the given direction with antenna gain (GT) (AlDalowi, Khoshnaw, \& QasMarrogy, 2017). A detailed explanation of the theoretical calculation of the link budget of satellite communication is presented in KYMETA (2019). Depending on the flow of information, the link budget can be analyzed for three types of links: Forward (FWD) link, Simple return (RTN) link, and Complex return (RTN) link. Figure 2 presents the direction of data flow among userterminal, hub, and Satellite.

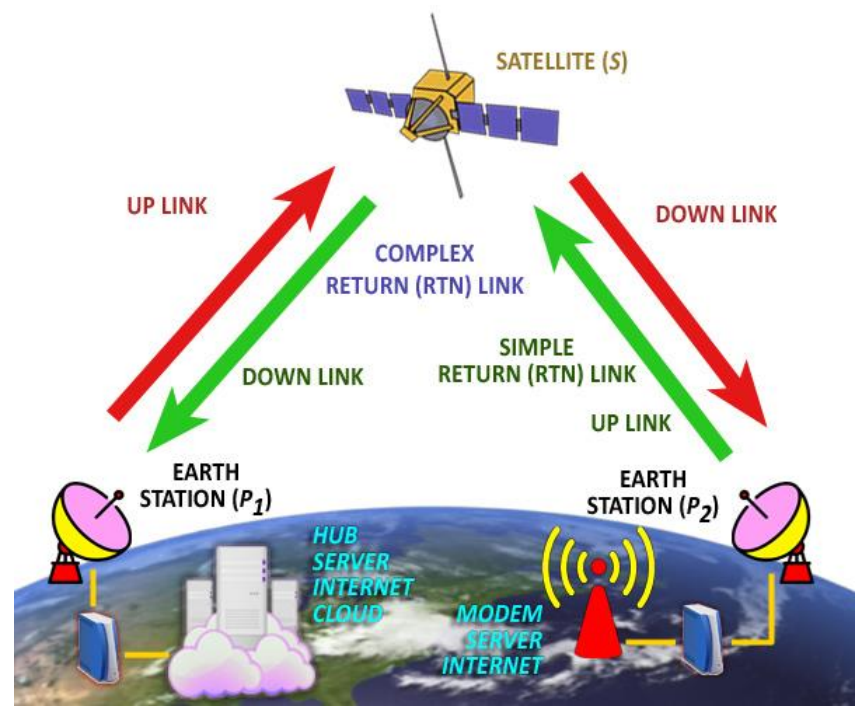

Figure 2: Direction of data flow through FWD \& RTN Links

Simplest calculation is needed for the FWD link as the hub can produce necessary uplink power to drive the FWD carrier up to the transponder limit of the satellite. As a result, for the FWD link budget analysis, only a portion of the link can be considered which basically connects the satellite and 
the user. A simple RTN link presents the up-link between user-terminal and satellite. It does not require any parameter of satellite or hub. Complex RTN link is considered as the total return link from terminal to satellite and satellite to the hub. Power received by the satellite from the terminal is not enough to drive the signal from the satellite to the hub and needs to be amplified. Signal to noise ratio (SNR) also needs to be calculated accurately for both links: terminal-satellite and satellite-hub links (KYMETA, 2019).

\section{LINK BUDGET ANALYSIS}

\section{A. Parameters of Transmitter Antenna}

Parameters of the transmitter antenna include the calculation of Wavelength, Antenna aperture, EIRP, Path loss, and C/N Ratio (CNR).

\section{i. Wavelength $(\tilde{\lambda})$}

Main properties of a wave signal (Electro-Magnetic Wave $(\operatorname{EMW}))$ are velocity $(\tilde{v})$, frequency $(f)$, and wavelength $(\tilde{\lambda})$. The velocity of EMW indicates the distance propagate over unit time, i.e. meter per second (how fast does a wave signal propagates in a certain medium). Speed of radio wave or light in a vacuum is indicated by $c$ and measured as $c=$ $299792458 \mathrm{~m} / \mathrm{s} \approx 300 \times 10^{6} \mathrm{~m} / \mathrm{s}$. Frequency indicates the number of complete vibrations of a particle of a certain medium while a wave signal is passing through, i.e. number of complete cycles per second (Hertz or $1 /$ second). Wavelength refers to the physical distance of a complete cycle of a wave signal which is measured in meters. The wavelength of a signal depends on the medium it travels through. Wavelength $(\tilde{\lambda})$ of EMW can be calculated based on the following formula as presented in Equation (1) (Mahmud \& Khan, 2009; Mir et al., 2018).

$\tilde{\lambda}=c / f$

\section{ii. Efficient Area of Transmitter Antenna}

Efficient area of Transmitter Antenna or Antenna Aperture (effective aperture, $A_{e T x}$ ) can be calculated using Equation (2) where $A_{T x}$ is the physical area, $r_{T x}$ is the radius, and $d_{T x}$ is the diameter of the antenna (Stutzman, 1998; Yaacob et $a l ., 2018)$. The efficiency of the antenna is presented by $\varepsilon_{T x}$. Antenna efficiency is determined based on the emitting capability of energy into the air.

$A_{e T x}=A_{T x} \varepsilon=\pi r_{T x}^{2} \varepsilon_{T x}=\pi\left(\frac{d_{T x}}{2}\right)^{2} \varepsilon_{T x}$

iii. Antenna Gain $\left(G_{T x}\right)$

Antenna Gain $\left(G_{T x}\right)$ can be calculated by using Equation (3) (Mahmud \& Khan, 2009; Ismail et al., 2017). Antenna gain presents the amount of radiated energy in a specific direction comparing with the amount of radiated energy of isotopic antenna in the same direction. In Equation (3), $\varepsilon_{T x}$ is antenna efficiency and $d_{T X}$ is the diameter of the transmitter antenna.

$G_{T x}=10 \log _{10}\left(\varepsilon_{T x}\left(\frac{\pi d_{T x}}{\tilde{\lambda}}\right)^{2}\right)$

\section{iv. Effective Isotropic Radiated Power (EIRP)}

The maximum amount of radiated power of the ideal isotropic antenna in a specific direction is called Effective Isotropic Radiated Power or Equivalent Isotropically Radiated Power (EIRP). EIRP can be calculated by Equation (4) which indicating summation of Antenna gain $\left(G_{T x}\right)$ and Forward power $\left(P_{f w d}\right)$ (Yulianto, 2012; Ismail et al., 2017; and Mir et al., 2018). Forward power is identified by the subtraction of Cable Loss $\left(L_{C T X}\right)$ from Transmitter output power $\left(P_{T x}\right)\left(P_{f w d}=P_{T x}-L_{C T x}\right)$. Measuring unit of EIRP is $d B i$ (decibels over isotropic).

$E I R P=G_{T x}+P_{f w d}=G_{T x}+\left(P_{T x}-L_{C T x}\right)$

\section{v. Path Loss or Free Space Path Loss (FSPL)}

FSPL is a kind of signal strength failure while electromagnetic wave travels through free space for a line of sight communication. Most of the radio frequency (RF) evaluations and dimensions are measured in the unit of decibels $(d B)$. FSPL can be calculated as presented in Equation (5) (Mahmud \& Khan, 2009; CS, 2016; and KYMETA, 2019). Here the distance of the satellite from the Earth station (Earth surface) is indicated as $d$ (or the distance from the transmitter to receiver in $\mathrm{km}$ ), and $f$ is the frequency in $\mathrm{MHz}$. Figure 3 presents behavioral graphs of FSPL on the variation of distance $(d)$ between Earth station and satellite for various frequencies of $\mathrm{X}$-band communication ranging from $8 \mathrm{GHz}$ to $12 \mathrm{GHz}$.

$F S P L=20\left(\log _{10} f+\log _{10} d\right)+32.44$

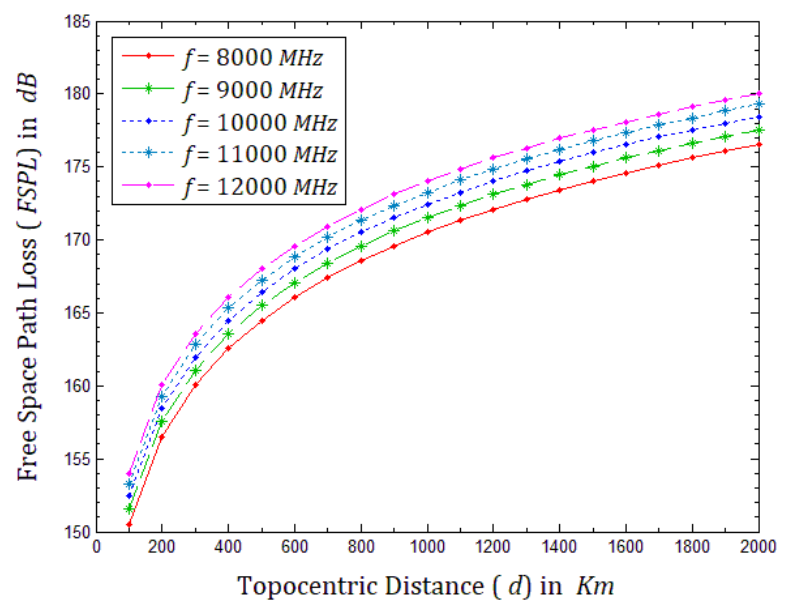

Figure 3: Behavior of FSPL over the variation of Topocentric distance (distance between Earth station \& Satellite) $(d)$ in range of X-band frequency $(f)(8 \mathrm{GHz}$ to $12 \mathrm{GHz}$ ) (Mahmud \& Khan, 2009; Song, \& Schnieder, 2019)

\section{v. Uplink C/N Ratio (CNR $\left.R_{T x}\right)$}

The carrier-to-noise ratio is written as $C N R$ or $\mathrm{C} / \mathrm{N}$ ratio. The term Signal-to-noise ratio $(S N R)$ is often used in some cases instead of $C N R$. To calculate uplink C/N Ratio $\left(C N R_{T x}\right)$ Equation (6) is used (KYMETA, 2019). Bandwidth is indicated by $b w$ in $\mathrm{Hz}, L_{a t m}$ is an atmospheric loss, $k_{\text {bolt }}$ is Boltzmann constant $\left(k_{\text {bolt }}=-228.6\right), G T_{T x}$ is gain to noise temperature or figure-of-merit of transmitter antenna, and $T_{T X}$ is system noise temperature.

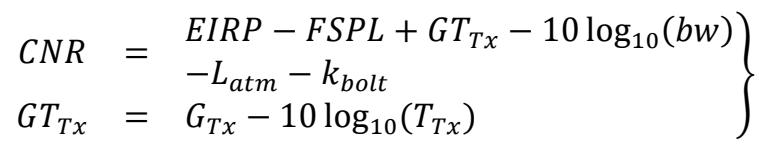

\section{B. Calculation of Satellite PFD}

Satellite power flux density (PFD) can be calculated based on the Equation (6) (Elbert, 2004; KYMETA, 2019).

$P F D=E I R P-10 \log _{10}\left(4 \pi d^{2}\right)$

Here, $d$ is the distance from the transmitter to receiver or path length and $b w$ is the reference bandwidth in $\mathrm{Hz}$. PFD 
presents the power per unit of bandwidth on the Earth surface.

\section{Azimuth ( $\alpha$ ) and Distance Analysis}

A maximum signal can be received by the earth station if it points the satellite directly. This can be ensured based on antenna look angles, which are: Azimuth angle $(\alpha)$ and Elevation angle $(\vartheta)$ (Cakaj, Keim, \& Malarić, 2007; Geyer, 2016). Azimuth is the clockwise angle created by an on-orbit satellite with North around an Earth station; and Elevation is defined as the angle at an Earth station created by the height of the on-orbit celestial body from the local horizon of the station. Figure 4 presents the concept of Azimuth angle $(\alpha)$ and Elevation angle $(\vartheta)$ of an Earth station $(P)$.

Azimuth angle $(\alpha)$ can be calculated by taking inverse tangent of the ratio of East $(e)$ and North $(n)$ as presented in Equation (7) for the $(e, n, u)$ coordinate frame.

$$
\alpha=\tan ^{-1}(e / n)
$$

Though the spherical earth model is used for analysis, the shape of the earth is mostly accepted as oblate spheroid (an ellipse moving in a circle about the minor axis) (Geyer, 2016). Because of the elliptical spheroid shape, simple calculation as in Euclidian space cannot be used, rather spherical geometry must be considered. Various methods such as, Haversine formula, Napier's cosine rule, Rightspherical triangle, Spherical trigonometry, etc. are applied by various researchers (Soler \& Eisemann, 1994; Mantoro, Akhtaruzzaman, Mahmud, \& Ayu, 2015; and Geyer, 2016).

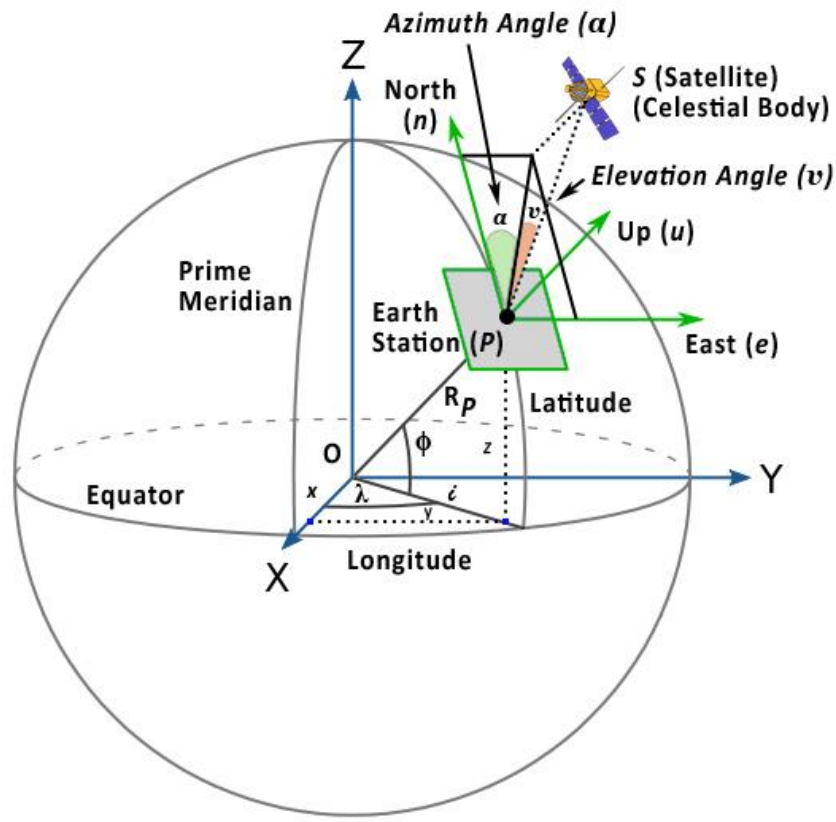

Figure 4: Conceptual Earth model for calculating Azimuth angle $(\alpha)$ and Elevation angle $(v)$ of Earth Station $(P)$ for pointing a Celestial Body $(S)$ (Soler \& Eisemann, 1994; Wang, Huynh, \& Williamson, 2013)

According to Geodetic Reference System 1980 (GRS-80) \& World Geodetic System 1984 (WGS-84), two important geometric parameters of Earth Spheroid are size $(a)$ and shape $(\zeta)$. Here $a$ is indicating the semi-major axis of Earth ( $a=6,378,137 \mathrm{~m}$ ) and $\zeta$ is indicating the flattening parameter of Earth shape $\left(\zeta^{-1}=298.257,223,563\right.$ ) (Soler $\&$ Eisemann, 1994; and Geyer, 2016). The semi-minor axis is indicated by $b(b=6,356,751 \mathrm{~m})$.
All the necessary calculations at the point of Earth station $(P)$ are with respect to the local geodetic coordinate system; East $(e)$, North $(n)$, and Up $(u)$ (Figure 4); which can be presented as $(e, n, u)$ coordinate at point $P$. Depending on the $(e, n, u)$ coordinate system, the components of PS (Earth station to Satellite in Figure 4) needs to be transformed into the components along $(x, y, z)$ coordinate frame at point $P$, which is parallel to the geocentric reference frame at point $O$. This transform can be performed by multiplying a rotational matrix $[R]$ as presented in Equation (8) (Soler, 1976; Soler \& Eisemann, 1994; and Wang, Huynh, \& Williamson, 2013).

$[R]=\left[\begin{array}{ccc}-\operatorname{Sin} \lambda & \operatorname{Cos} \lambda & 0 \\ -\operatorname{Sin} \phi \operatorname{Cos} \lambda & -\operatorname{Sin} \phi \operatorname{Sin} \lambda & \operatorname{Cos} \phi \\ \operatorname{Cos} \phi \operatorname{Cos} \lambda & \operatorname{Cos} \phi \operatorname{Sin} \lambda & \operatorname{Sin} \phi\end{array}\right]$

Thus, the equation of $(e, n, u)$ coordinate becomes, as presented in Equation (9). Here $\left(x_{s}, y_{s}, z_{s}\right)$ and $\left(x_{p}, y_{p}, z_{p}\right)$ are the coordinates of Satellite $(S)$ and Earth station $(P)$.

$\left[\begin{array}{l}e \\ n \\ u\end{array}\right]=[R]\left[\begin{array}{l}x \\ y \\ z\end{array}\right]=[R]\left\{\left[\begin{array}{l}x_{s} \\ y_{s} \\ z_{s}\end{array}\right]-\left[\begin{array}{l}x_{p} \\ y_{p} \\ z_{p}\end{array}\right]\right\}$

The rectangular coordinate $(x, y, z)$ of Earth station $(P)$ and Satellite $(S)$ can be calculated based on the well-known curvilinear geodetic expressions as presented in Equation (10) (Soler, 1976; Soler \& Eisemann, 1994; Geyer, 2016; Panou, Korakitis, \& Delikaraoglou, 2018; and Medvedev et al., 2018). Here, $N$ is indicating the principal radius (Prime Vertical Radius) of curvature which is determined using Equation (11) (Geyer, 2016; Panou, Korakitis, \& Delikaraoglou, 2018; and Medvedev et al., 2018). Geodetic height (Ellipsoidal height) is indicated by $H_{P}$.

$\left[\begin{array}{l}x \\ y \\ Z\end{array}\right]=\left[\begin{array}{c}\left(N+H_{P}\right) \operatorname{Cos} \phi \operatorname{Cos} \lambda \\ \left(N+H_{P}\right) \operatorname{Cos} \phi \operatorname{Sin} \lambda \\ {\left[N\left(1-\sigma^{2}\right)+H_{P}\right] \operatorname{Sin} \phi}\end{array}\right]$
$N=a / \sqrt{\left(1-\sigma^{2} \operatorname{Sin}^{2} \phi\right)}$

The eccentricity of the Earth ellipsoid is presenting by $\sigma$. Square of the eccentricity $(\sigma)$ is used in most of the cases of calculation and is presented in Equation (12). Equation (13) and Equation (14) are presenting necessary formulas and values of the flattening parameter of Earth shape $(\zeta)$ and other parameters.

$\sigma^{2}=\frac{a^{2}-b^{2}}{a^{2}}=\zeta(2-\zeta)$

$\zeta=\frac{a-b}{a}$

$a=$ semimajor axis $=6,378,137 \mathrm{~m}$

$\zeta^{-1}=298.257,223,563$

$b=$ semiminor axis $=(1-\zeta) a=6,356,751 \mathrm{~m}$

$\sigma^{2}=0.006,694,379,990,14$

Depending on Equation (10), geodetic longitude $(\lambda)$ and latitude $(\phi)$ of Earth station $(P)$ can be obtained from the elements of the matrix, as presented in Equation (15) where, $i$ is the horizontal projection of $R_{P}$ as shown in Figure $4, R_{P}$ (Geocentric radius) is the distance of Earth station $(P)$, and $\alpha_{\text {rad }}$ is the radian value of azimuth angle $(\alpha)$ (Panou, Korakitis, \& Delikaraoglou, 2018; and Medvedev et al., 2018). 


$$
\left.\begin{array}{l}
\lambda=\tan ^{-1}\left(\frac{y}{x}\right) \\
\phi=\tan ^{-1}\left(\frac{z}{i}\right) \\
i=\sqrt{x^{2}+y^{2}}=\left(N+H_{P}\right) \operatorname{Cos} \phi \\
R_{P}=\sqrt{i^{2}+z^{2}}=\left(N+H_{P}\right) \\
\alpha_{\text {rad }}=\alpha(\pi / 180)
\end{array}\right\}
$$

Three concepts of Earth radius can be formulated as the function of latitude $(\phi)$ as presented in Equation (16). Thus, the Earth radius varies if the $\phi$ changes. Figure 5 shows the characteristic graphs of three types of radii: Geocentric, Meridional, and Prime vertical; where latitude changes from $0^{\circ}$ to $90^{\circ}$. In this study, the prime vertical radius concept is applied for most of the calculations.

$$
\left.\begin{array}{rl}
R(\phi) & =\left(\frac{\left(a^{2} \cos \phi\right)^{2}+\left(b^{2} \sin \phi\right)^{2}}{(a \cos \phi)^{2}+(b \sin \phi)^{2}}\right)^{1 / 2} \\
M(\phi) & =\frac{a\left(1-\sigma^{2}\right)}{\left(1-\sigma^{2} \sin ^{2} \phi\right)^{3 / 2}} \\
N(\phi) & =\frac{a}{\left(1-\sigma^{2} \sin ^{2} \phi\right)^{1 / 2}}
\end{array}\right\}
$$

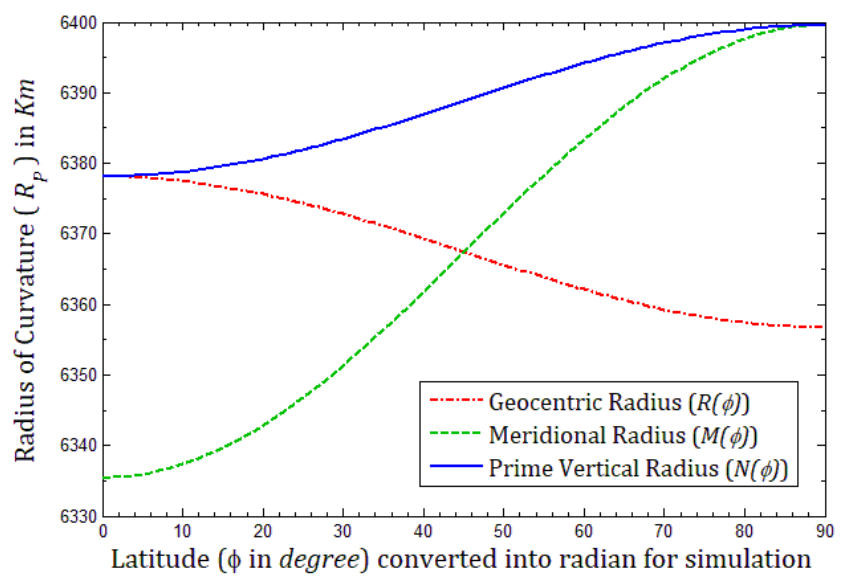

Figure 5: Characteristics of radius changes in the variation of Latitude $(\phi)$ from $0^{\circ}$ to $90^{\circ}$; Geocentric $R(\phi)$, Meridional $M(\phi)$, and Prime Vertical $N(\phi)$ Radiuses. In this study, the prime vertical radius is considered (Geyer, 2016).

Azimuth angle $(\alpha)$ and point to point distance (topocentric distance, $d$ ) between earth station $(P)$ and celestial body $(S)$ can also be determined by using the spherical geometric approximation as presented in Figure 6 . Here, $P, \lambda$, and $\phi$ are presenting the position, Longitude, and Latitude of Earth station. The straight-line distance $O S$ between Geo-center $(O)$ and Satellite $(S)$ intersects the Earth Equator at point $U$ is indicated as the sub-satellite point on Earth surface. From triangle $\triangle S O P$, distance $d$ (topocentric distance) is possible to determine by Equation (17) where $r(O S)$ and $R_{P}(O P)$ can be known from Equation (10). Here, $r$ represents the geocentric distance of Satellite $(S)$ from Earth center $(O)$.

Now, by applying Napier's rules on the spherical rightangled triangle $(\triangle U V P)$, the angle $\gamma(\angle U O P)$ can be determined by applying the cosine rule as shown in Equation (18) (Soler \& Eisemann, 1994; Hyde \& Bargellini, 2002). It is important to know that, in the triangle $\triangle U V P ; \angle P V U=$ $90^{\circ}, \angle P V O=90^{\circ}$, and $\angle P U O=90^{\circ}$. Figure 7 explains that the Azimuth angle $(\alpha)$ is a function of angle $\beta$. By applying Napier's rule, $\angle \beta$ can be calculated as presented in Equation (19) (Soler \& Eisemann, 1994; Hyde \& Bargellini, 2002; Geyer, 2016). Possible calculation of $\alpha$ as a function of
Satellite location coordinate (function of angle $\beta$ ) on the horizon of Earth station $(P)$ is presented in Figure 7; if Satellite is in $N E$ (North-East) coordinate with respect to Earth station, $\alpha$ is equal to $\beta(\alpha=\beta)$; for $S E$ (South-East) coordinate, $\alpha=180^{\circ}-\beta$; for $S W$ (South-West) coordinate, $\alpha=180^{\circ}+\beta$, and for $N W$ (North-West) coordinate, $\alpha=$ $2\left(180^{\circ}\right)-\beta$.

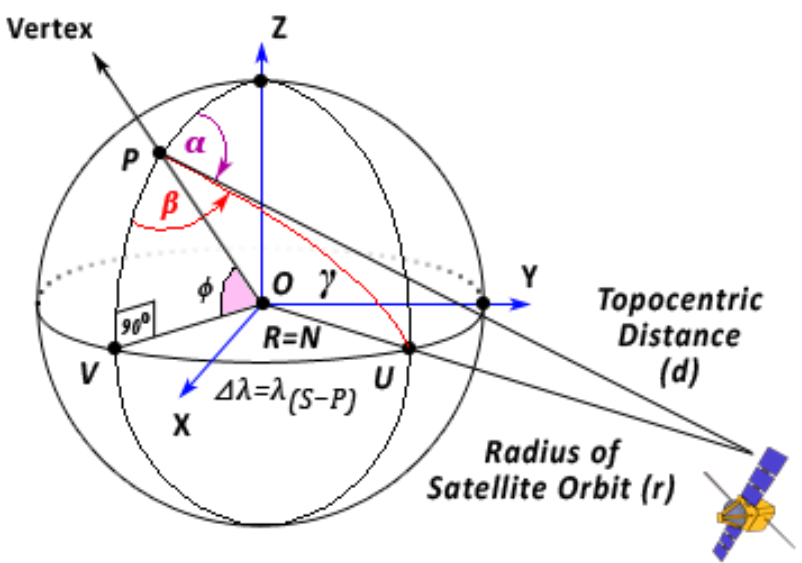

EARTH

Satellite (S)

(Conceptual Model)

\section{Spherical geometric approximation of EARTH model \\ [Determining Azimuth Angle $(\alpha)$ as a function of $\beta$ ].}

Figure 6: Spherical geometric approximation to determine Azimuth angle $(\alpha)$ as a function of angle $\beta$ and the location of Satellite $(S)$ with respect to Earth station $(P)$ (Soler \& Eisemann, 1994; Hyde \& Bargellini, 2002; Roddy, 2006)

$d=\sqrt{\left(r^{2}+R_{p}^{2}-2 r R_{p} \operatorname{Cos} \gamma\right)}$

$\operatorname{Cos} \gamma=\operatorname{Cos} \phi \operatorname{Cos}\left(\lambda_{s}-\lambda\right)$

$\beta=\operatorname{Cos}^{-1}(\operatorname{Cot} \gamma \operatorname{Tan} \phi)$

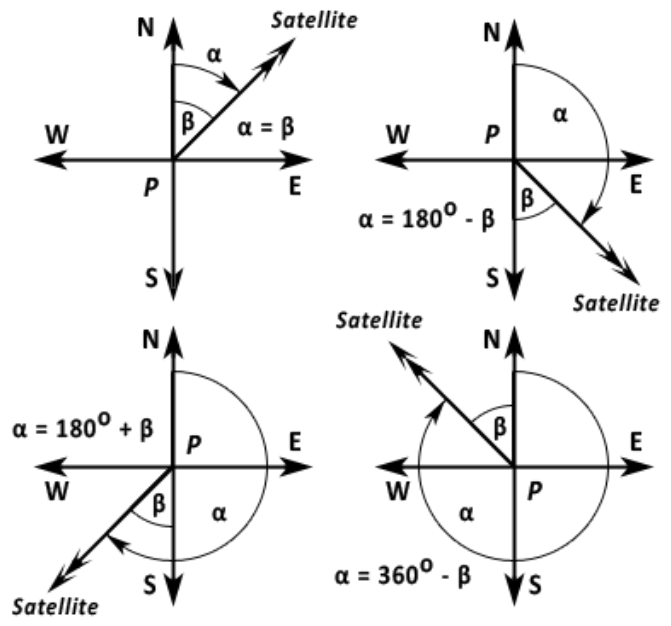

Figure 7: Concept of Azimuth angle $(\alpha)$ as a function of the location of Satellite $(S)(\angle \beta)$ with respect to Earth station $(P)$

(Soler \& Eisemann, 1994; Roddy, 2006)

\section{Rain Attenuation Analysis}

Rain attenuation refers to the degradation of Microwave Radio Frequency (MRF) signal caused by the electromagnetic interference of atmospheric rain, snow, or 
ice. Attenuation can be influenced a lot for the frequency band $10 \mathrm{GHz}$ or more by the rain and precipitation (Kestwal, 2014; Shrestha \& Choi, 2017). The phenomenon of rain attenuation is related to the amount of rainfall and frequency which leads to increasing path loss, restricting the scope of coverage, thus debasing the system performance. Communication for wireless networks depends on several parameters such as, elevation angle $(\vartheta)$ of Earth station, path loss, specific and predicted attenuation.

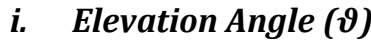

The elevation angle of the earth station is defined by the angle $v$ of the antenna created by the height of Satellite $(S)$ from the local horizon of the earth station $(P)$, the concept is presented earlier in Figure 4 (Soler \& Eisemann, 1994). Rain attenuation also depends on the Elevation angle which can be calculated by Equation (20) for the $(e, n, u)$ coordinate frame of point $P$ (Figure 4 ).

$\vartheta=\tan ^{-1}\left(\frac{u}{\sqrt{e^{2}+n^{2}}}\right)$

\section{ii. Slant Path Length $\left(L_{s}\right)$}

Slant path through rain depends on the Elevation angle of Earth station; low Elevation angle means long Slant path thus rain has more effect and causes high rain attenuation. Concept of slant path length $\left(L_{s}\right.$ in $\left.\mathrm{km}\right)$ as the function of rain height and elevation angle is presented in Figure 8. According to the figure, $L_{s}$ will be greater for lesser elevation angle $(\vartheta)$; such as, $L_{s 1}>L_{s 3}$ for Earth station $\left(P_{1}\right)$ to Satellite $S_{1}$ and $S_{2}$ as $\vartheta_{1}<\vartheta_{2}$. Slant Path Length $\left(L_{S}\right)$ can be calculated by using Equation (21) (Kanellopoulos, 2000; ITU-R, 2003a; Adhikari et al., 2011; Nuroddin et al., 2013; Lwas, et al., 2015; Shrestha, \& Choi, 2017, 2019; and Hossain \& Islam, 2017; Fadilah, \& Pratama, 2018). Rain height and the average height of Earth station $(P)$ above sea level are presented as $H_{r}$ and $H_{P}$. Horizontal projection $\left(L_{g}\right)$ of slant path length is calculated based on Equation (22) (ITU-R, 2003a; Adhikari et al., 2011; Nuroddin et al., 2013; Hossain \& Islam, 2017; Fadilah, \& Pratama, 2018).

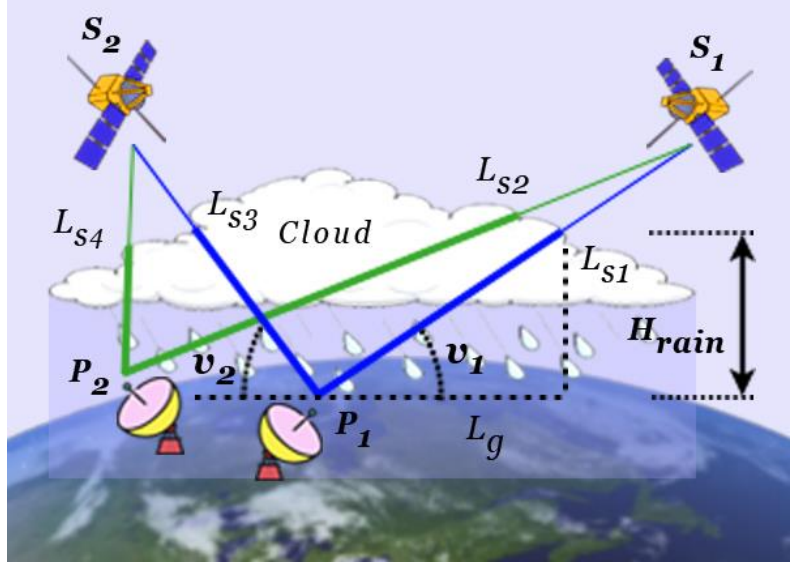

Figure 8: Concept of Slant Path and Slant Path Length $\left(L_{S}\right)$ as a function of Elevation angle $(\vartheta)$ and Rain height $\left(H_{r}\right)$ (ITU-R, 2003a; Adhikari et al., 2011; Nuroddin et al., 2013; and Hossain \& Islam, 2017)

$L_{S}=\left(H_{r}-H_{P}\right) / \sin \vartheta$

$L_{g}=L_{S} \cos \vartheta$

\section{iii. Specific Attenuation $\left(A_{S}\right)$}

Specific attenuation $\left(A_{S}\right)$ indicates the rain attenuation per unit distance $(\mathrm{dB} / \mathrm{km})$. It is a fundamental element in calculating rain attenuation for a slant path. Model of predicted rain attenuation also depends on the value of $A_{S}$. Specific attenuation can be determined by using the powerlaw as presented in Equation (23) (Ippolito, 1986; Nuroddin et al., 2013; Kestwal, Joshi, \& Garia, 2014; Hossain \& Islam, 2017; RACOM, 2018; Fadilah, \& Pratama, 2018; and Shrestha, \& Choi, 2017, 2019). Here, Rain rate presents rainfall rate in $\mathrm{mm}$ per hour exceeded for $0.01 \%$ of the average year which can be calculated from Equation (24) where Rain $_{\text {max }}$ is rainfall in $\mathrm{mm}$, and $T$ is the time interval in minutes (Kestwal, Joshi, \& Garia, 2014).

$A_{S}=k\left(\text { Rain }_{\text {rate }}\right)^{\omega}$

Rain $_{\text {rate }}=$ Rain $_{\text {max }}\left(\frac{60}{T}\right)$

If Rain $_{\text {rate }}$ is 0 (zero), there will be no attenuation (due to rainfall) for RF propagation. The values of $k$ and $\omega$ depend on frequency (range: 1 to $1,000 \mathrm{GHz}$ ) and polarization of electromagnetic (EM) wave. The values of these parameters can be calculated from Equation (25) which is derived from curve-fitting and power-law coefficients. Values of the necessary parameters can be obtained from the references included in the reference section (ITU-R, 2003b; ITU-R, 2005; Kestwal, Joshi, \& Garia, 2014).

$\left.\begin{array}{l}\log k=\sum_{j=1}^{4}\left(a_{j} \exp \left[-\left(\frac{\log f-b_{j}}{c_{j}}\right)^{2}\right]\right)+m_{k} \log f+c_{k} \\ \omega=\sum_{j=1}^{5}\left(a_{j} \exp \left[-\left(\frac{\log f-b_{j}}{c_{j}}\right)^{2}\right]\right)+m_{\omega} \log f+c_{\omega}\end{array}\right\}$

The values of $k$ and $\omega$ can also be determined through interpolation of the logarithmic scale for $k$ and linear for $\omega$. The popular equation for determining $k$ and $\omega$ is presented in Equation (26) (ITU-R, 2003b; ITU-R, 2005; Nuroddin et al., 2013; Yussuff, \& Khamis, 2013). These equations are used to determine specific rain attenuation for the designed Link Budget Tool for X-Band satellite communication as presented in this manuscript.

$\left.\begin{array}{l}k=\frac{\left(k_{H}+k_{v}+\left(k_{H}-k_{v}\right) \cos ^{2} \vartheta \cos 2 \tau\right)}{2} \\ \omega=\frac{k_{H} \omega_{H}+k_{v} \omega_{v}+\left(k_{H} \omega_{H}-k_{v} \omega_{v}\right) \cos ^{2} \vartheta \cos 2 \tau}{2 k}\end{array}\right\}$

Here $\vartheta$ is elevation angle and $\tau$ is polarization tilt angle relating to horizon values of frequency-dependent coefficients, $k_{H}, k_{v}, \omega_{H}$, and $\omega_{v}$ were determined from the listed values presented in the references; ITU-R (2003b), ITU-R (2005), Nuroddin et al. (2013), and Yussuff, \& Khamis (2013).

\section{iv. Effective Path Length $\left(L_{E}\right)$}

Effective path length $\left(L_{E}\right)$ is the average length of the slant path $\left(L_{S}\right)$ through the cell of uniform rain. Thus, $L_{E}$ is always smaller than $L_{S}$ which leads to the factors of vertical and horizontal path reduction (Mello \& Pontes, 2012). In this Link-budget tool design, the effective path length is calculated using Equation (27) (Nuroddin et al., 2013, Yussuff, \& Khamis, 2013; Abdullah, Ismail, Badron, \& Hashim, 2018).

$L_{E}=L_{R} v_{0.01}$ 
Here, $L_{R}$ is reduced path length and $v_{0.01}$ is a vertical adjustment factor (for over $0.01 \%$ of the average year). The value of $L_{R}$ depends on horizontal adjustment factor $\left(r_{0.01}\right)$ for over $0.01 \%$ of the average year and the value of new elevation angle $(\bar{\vartheta})$ which are determined from Equation (28) to Equation (32) (Nuroddin et al., 2013, Yussuff, \& Khamis, 2013; Zhiger, 2017; Abdullah, Ismail, Badron, \& Hashim, 2018). In Equation (32), $\chi$ is measured in degree and $\phi$ is the latitude of the earth station.

$$
\begin{aligned}
& r_{0.01}=\frac{1}{1+\left(0.78 \sqrt{\frac{\operatorname{Lg}_{S}}{f}}\right)-0.38\left(1-e^{-2 L g}\right)} \\
& \bar{\vartheta}=\tan ^{-1}\left(\frac{H_{r}-H_{P}}{L_{g} r_{0.01}}\right)
\end{aligned}
$$

$L_{R}= \begin{cases}\frac{L_{g} r_{0.01}}{\operatorname{Cos} \vartheta} & \text { if } \bar{\vartheta}>\vartheta \\ \frac{H_{r}-H_{P}}{\operatorname{Sin} \vartheta} & \text { if } \bar{\vartheta} \leq \vartheta\end{cases}$

$v_{0.01}=\frac{1}{1+\sqrt{\operatorname{Sin} \vartheta}\left(31\left(1-e^{-\left(\frac{\vartheta}{1+\chi}\right)}\right)\left(\frac{\sqrt{L_{R} A_{S}}}{f^{2}}\right)-0.45\right)}$

$\chi= \begin{cases}(36-|\phi|) & \text { if }|\phi|<36^{\circ} \\ 0 & \text { if }|\phi| \geq 36^{\circ}\end{cases}$

\section{ix. Predicted attenuation $\left(A_{p}\right)$}

Predicted rain attenuation $\left(A_{p}\right)$ exceeded for $0.01 \%$ of an average year can be calculated by Equation (33) where $A_{S}$ and $L_{E}$ are the specific attenuation and effective path length respectively. Effective path length vs. predicted attenuation graphs for various rain rates are presented in Figure 9.

$A_{p}=A_{S} L_{E}$

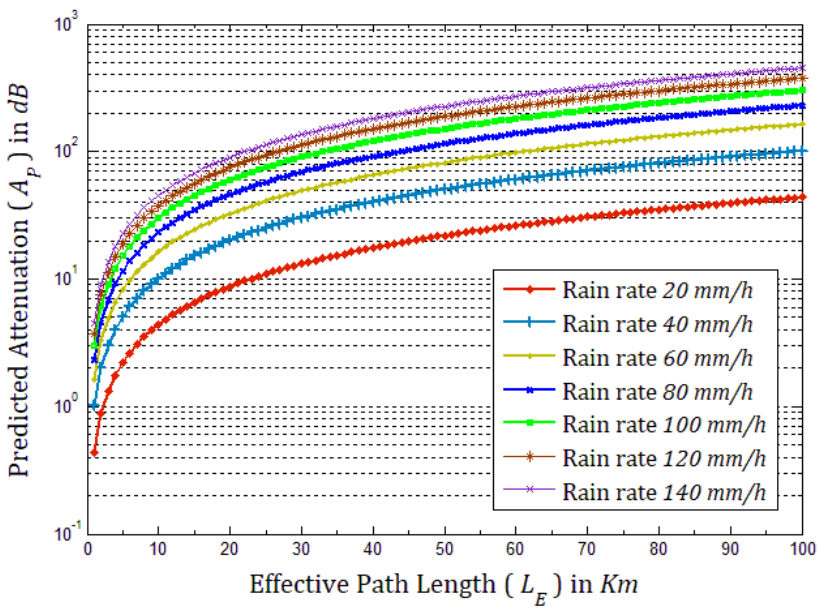

Figure 9: Predicted Attenuation $\left(A_{P}\right)$ behavior over the variation of Effective Path Length $\left(L_{E}\right)$ for various rain rate situation (Al-Saegh, et al., 2014; Panchal \& Joshi, 2016; Kestwal, Joshi, \& Garia, 2014)

\section{E. Parameters of Receiver Antenna}

Wavelength $(\tilde{\lambda})$, Efficient area of receiver antenna $\left(A_{e R x}\right)$, Receiver antenna gain $\left(G_{R x}\right)$, and Effective Isotropic Radiated Power $\left(E I R P_{S a t}\right)$ can be determined using equations from (1) to (4) where $\varepsilon_{R x}, d_{R x}$, and $P_{R x}$ should be used as efficiency, diameter of receiver antenna, and receiver power, respectively.

\section{i. Link Margin or Weather Margin $\left(W_{m}\right)$}

Link margin, Fade margin, or Weather margin $\left(W_{m}\right)$ defines the margin of safety of received signal power while a temporary attenuation or signal fading occurs at the receiver antenna. Determining the optimum link margin is very important because a small margin will make the link unstable and a large margin will make the link expensive. Though, selection of $W_{m}$ is an iterative and arbitrary process and depends on the knowledge of the designer, it is related to the receiver's sensitivity. Weather margin $\left(W_{m}\right)$ can be calculated by using Equation (34) (TRANZEO, 2010; CS, 2016; RACOM, 2018).

$W_{m}=P_{R x}-S_{R x}$

The power level $\left(P_{R x}\right)$ arrived at receiver as input signal can be derived by Equation (35). Receiver sensitivity $\left(S_{R x}\right)$ is related to the units of microvolt $(\mu V)$ which needs to be converted into unit of power $(\mathrm{dBm})$. The conversion method is presented in Equation (36) (CS, 2016), where $V$ is $r m s$ voltage of $\mu V, R_{\Omega}$ is the resistance of the system, and $\rho$ is a constant factor ( $\rho=30$ for RF320 series).

$P_{R x}=P_{T x}-L_{C T x}+G_{T x}-F S P L_{T x}+G_{R x}-L_{C R x}$

$S_{R x}=10 \log _{10}\left[\frac{\left(V 10^{-6}\right)^{2}}{R_{\Omega}}\right]+\rho$

\section{ii. Rx Antenna G/T $\left(G T_{R x}\right)$}

Earth station antenna gain-to-noise-temperature ( $G / T$ or $\left.G T_{R x}\right)$ is figure-of-merit which presents the performance of the receiver antenna (Capela, 2012). Value of $G / T$ is usually expressed in $d B K^{-1}$ and can be determined by Equation (37) (Al-Dalowi, Khoshnaw, \& QasMarrogy, 2017; KYMETA, 2019). Here $G_{R x}$ is antenna gain of receiver and $T_{R x}$ is system noise temperature.

$G T_{R x}=G_{R x}-\left(10 \log _{10} T_{R x}\right)$

\section{iii. Down Link Path Loss ( $\left.P L_{R x}\right)$}

Down link free space path loss $\left(L_{R x}\right)$ can be determined by Equation (38) (Elechi, \& Otasowie, 2016; Ranjan, et al., 2018). Here $d$ is indicating the distance of the satellite from the receiver antenna. Characteristic graphs of down link path loss of the X-band frequency range for the variation of Topocentric distance are shown in Figure 10.

$P L_{R x}=20 \log _{10}(4 \pi d / \tilde{\lambda})$

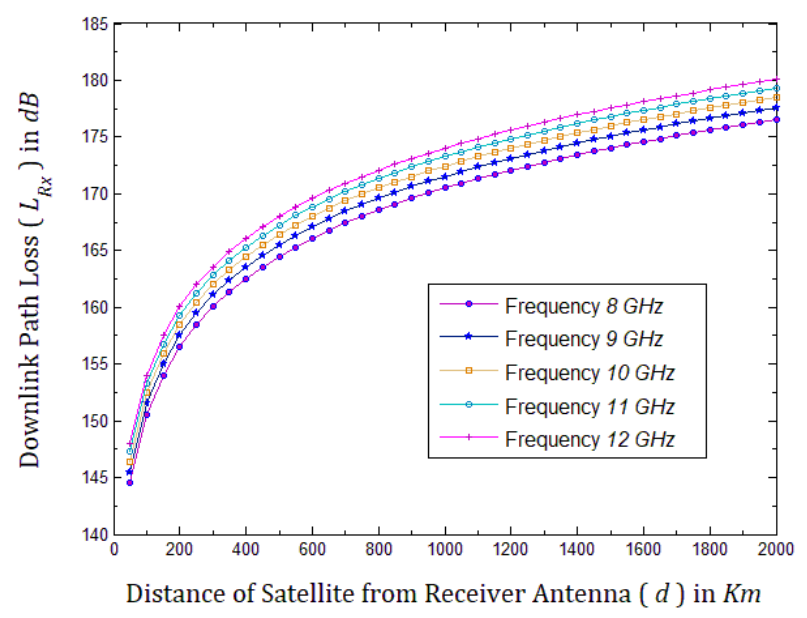

Figure 10: Characteristics of Downlink Path Loss $\left(P L_{R x}\right)$ over Topocentric distance $(d)$ for frequency ranges: $8 \mathrm{GHz}-12 \mathrm{GHz}$ (Bazzi, Giorgetti, Pasolini, \& Schena, 2005; Elechi, \& Otasowie, 2016; Ranjan, et al., 2018; Song, \& Schnieder, 2019) 


\section{iv. Down Link C/N Ratio $\left(C N R_{R x}\right)$}

Down link Career to Noise Ratio (downlink C/N Ratio or $C N R_{R x}$ ) can be ascertained by Equation (39) (Mebrek, Abderrahmane, Himeur, \& Bendoukha, 2012; KYMETA, 2019). Here, Boltzmann's constant is defined as $k_{\text {bolt }}=$ -228.6 , the atmospheric loss is indicated as $L_{a t m}$, and bandwidth is indicated as $b w$.

$$
C N R_{R x}=\begin{array}{ll}
E I R P_{S a t}-P L_{R x}-10 \log _{10}(b w) \\
-L_{C R x}+G T_{R x}-k_{b o l t}+W_{m}-L_{a t m}
\end{array}
$$

\section{DESIGN OF THE LINK-BUDGET TOOL}

Link analysis for satellite communication (link budget) is basically the theoretical study and mathematical modeling of the satellite system resembling the behavior of RF signal propagation and transmission. The analytical model comprised of some input parameters through which some output values are determined to predict some necessary parameters for the establishment of an RF satellite link. Table 1 presents input and output parameters that are necessary for satellite link budget analysis and design of the Link Budget web application tool.

Table 1

Parameters in designing Link Budget Tool for military X-band satellite communication

\begin{tabular}{|c|c|c|}
\hline $\begin{array}{l}\text { ANALYSIS } \\
\text { POINTS } \\
\end{array}$ & $\begin{array}{c}\text { INPUT } \\
\text { PARAMETERS } \\
\end{array}$ & $\begin{array}{c}\text { OUTPUT } \\
\text { PARAMETERS }\end{array}$ \\
\hline $\begin{array}{l}\text { TRANSMITTER } \\
\text { ANTENNA }\end{array}$ & $\begin{array}{l}\text { Speed of light }(c) \text {, } \\
\text { Frequency }(f) \text {, } \\
\text { Diameter }\left(d_{T x}\right) \text {, } \\
\text { Efficiency }\left(\varepsilon_{T x}\right) \text {, } \\
\text { Output power }\left(P_{T x}\right) \text {, } \\
\text { Cable loss }\left(L_{C T x}\right) \text {, } \\
\text { Distance: Antenna to Satellite }(d) \text {, } \\
\text { Boltzmann cons. }\left(k_{\text {bolt }}\right) \text {, } \\
\text { Bandwidth }(b w)\end{array}$ & $\begin{array}{l}\text { Wavelength }(\tilde{\lambda}) \text {, } \\
\text { Effective area }\left(A_{e T x}\right) \text {, } \\
\text { Gain }\left(G_{T x}\right) \text {, } \\
E I R P, \\
F S P L, \\
G T_{T x} \\
\text { Uplink C/N ratio } C N R_{T x}\end{array}$ \\
\hline SATELLITE & $E I R P, \& d$ & Satellite Power Flex Density $(P F D)$ \\
\hline $\begin{array}{l}\text { AZIMUTH AND } \\
\text { DISTANCE }\end{array}$ & $\begin{array}{l}\text { Antenna position }\left(x_{p}, y_{p}, z_{p}\right) \text {, } \\
\text { Satellite position }\left(x_{s}, y_{s}, z_{s}\right) \text {, } \\
\text { Rotation Matrix }[R], \\
\text { Latitude }(\phi) \text {, } \\
\text { Longitude }(\lambda) \text {, } \\
\text { Geodetic height }\left(H_{P}\right)\end{array}$ & $\begin{array}{l}(e, n, u) \text { coordinate, } \\
\text { Azimuth angle }(\alpha) \text {, } \\
\text { Principal radius }(N) \text {, } \\
\text { Eccentricity }(\sigma) \text {, } \\
\text { Flattening }(\zeta) \text {, } \\
\text { Topocentric dist. }(d) \text {, } \\
\text { Angle }(\angle \beta)\end{array}$ \\
\hline $\begin{array}{l}\text { RAIN } \\
\text { ATTENUATION }\end{array}$ & $\begin{array}{l}(e, n, u) \text { coordinate, } \\
\text { Rain height }\left(H_{r}\right), \\
\text { Geodetic height }\left(H_{P}\right), \\
\text { Rain rate }\left(\text { Rain }_{\text {Rate }}\right) \text {, } \\
\text { Polarization factors }(k), \\
\text { Constant coefficient }(\omega) \text {, } \\
\text { Principal radius }(N)\end{array}$ & $\begin{array}{l}\text { Elevation angle }(\vartheta) \text {, } \\
\text { Slant path length }\left(L_{S}\right) \text {, } \\
\text { Horizontal projection }\left(L_{g}\right) \text {, } \\
\text { Specific attenuation }\left(A_{S}\right) \text {, } \\
\text { Effective path length }\left(L_{E}\right) \text {, } \\
\text { Reduced path length }\left(L_{R}\right) \text {, } \\
\text { Horizontal \& vertical adjustment factors }\left(r_{0.01} \& v_{0.01}\right) \text {, } \\
\text { Predicted attenuation }\left(A_{P}\right)\end{array}$ \\
\hline $\begin{array}{l}\text { RECEIVER } \\
\text { ANTENNA }\end{array}$ & $\begin{array}{l}\text { Transmitter power }\left(P_{T x}\right) \text {, } \\
\text { Transmitter \& receiver cable loss }\left(L_{C T x} \& L_{C R x}\right) \text {, } \\
\text { Transmitter gain }\left(G_{T x}\right) \text {, } \\
F S P L_{T x} \text {, } \\
\text { RMS of } \mu V(V) \text {, } \\
\text { Constant factor }(\rho) \text {, } \\
\text { System resistance }\left(R_{\Omega}\right) \text {, } \\
\text { System noise temperature }\left(T_{R x}\right) \text {, } \\
\text { Topocentric dist. }(d) \text {, } \\
\text { Boltzmann's constant }\left(k_{b o l t}\right), \\
\text { Atmospheric loss }\left(L_{a t m}\right)\end{array}$ & $\begin{array}{l}\text { Wavelength }(\tilde{\lambda}) \text {, } \\
\text { Effective area }\left(A_{e R x}\right) \text {, } \\
\text { Gain }\left(G_{R x}\right) \text {, } \\
E I R P_{S a t}, \\
\text { Power level }\left(P_{R x}\right) \text {, } \\
\text { Sensitivity }\left(S_{R x}\right) \text {, } \\
\text { Weather margin }\left(W_{m}\right) \text {, } \\
\text { Antenna G/T }\left(G T_{R x}\right) \\
\text { Down link path loss }\left(P L_{R x}\right) \text {, } \\
\text { Down link C/N }\left(C N R_{R x}\right)\end{array}$ \\
\hline
\end{tabular}

The web-application tool is developed based on HTML, PHP, Javascript, and MySQL. The database is designed at the back end to store user information and calculated data. The web-application tool is designed so that the tool can be used through the internet from anywhere. The tool also can be used in portable devices independently on the local server, if necessary. Javascript (scripting language) is used for necessary calculation, thus for any calculation command the tool responds very fast in producing necessary results without reloading the web tool. Ajax script is used for submitting and retrieving data to and from the server.

\section{A. Conceptual Diagrams and Design}

Users of the Link Budget tool are categorized mainly into two types; firstly, the Unregistered users, who can access the tool to perform all the available calculations without saving or retrieving any action; secondly, the Registered users, who have to login the system to perform necessary calculations. 
Registered users again categorized into two: Active-user and Peer-user. Active-user has access to change input parameters, store and retrieve data, view usages histories, and create Peer-users. On the other hand, Peer-user can only view the calculated results of its corresponding Active-user. In military activity, some troops who are connected with Earth Station through modem, hub, WiFi, or Cloud; may need to know the status and related information of satellite links. To support this notion, the Peer-user concept is adopted in this design. Active-user will be at the Earth Station while Peer-users are in mobile on the ground.

The process flow diagram of the designed web-application tool is presented in Figure 11. At the beginning stage, unregistered users have access to use the Web Tool. Registered users will $\log$ in to the system by using their username and password. Depending on the access permission, users will be directed to their corresponding page. At this stage, both users will view last updated information where Peer-users will view only the calculated information and Active-users will view all the necessary input and output parameters. Active-users will be able to change input parameter values when required and use the "Calculate" button for performing the new calculation. For a successful calculation, the system will display the updated results and send an Ajax request to store the updated information into the server. For a better understanding of the system, a conceptual Data Flow Diagram (DFD) is presented in Figure 12.

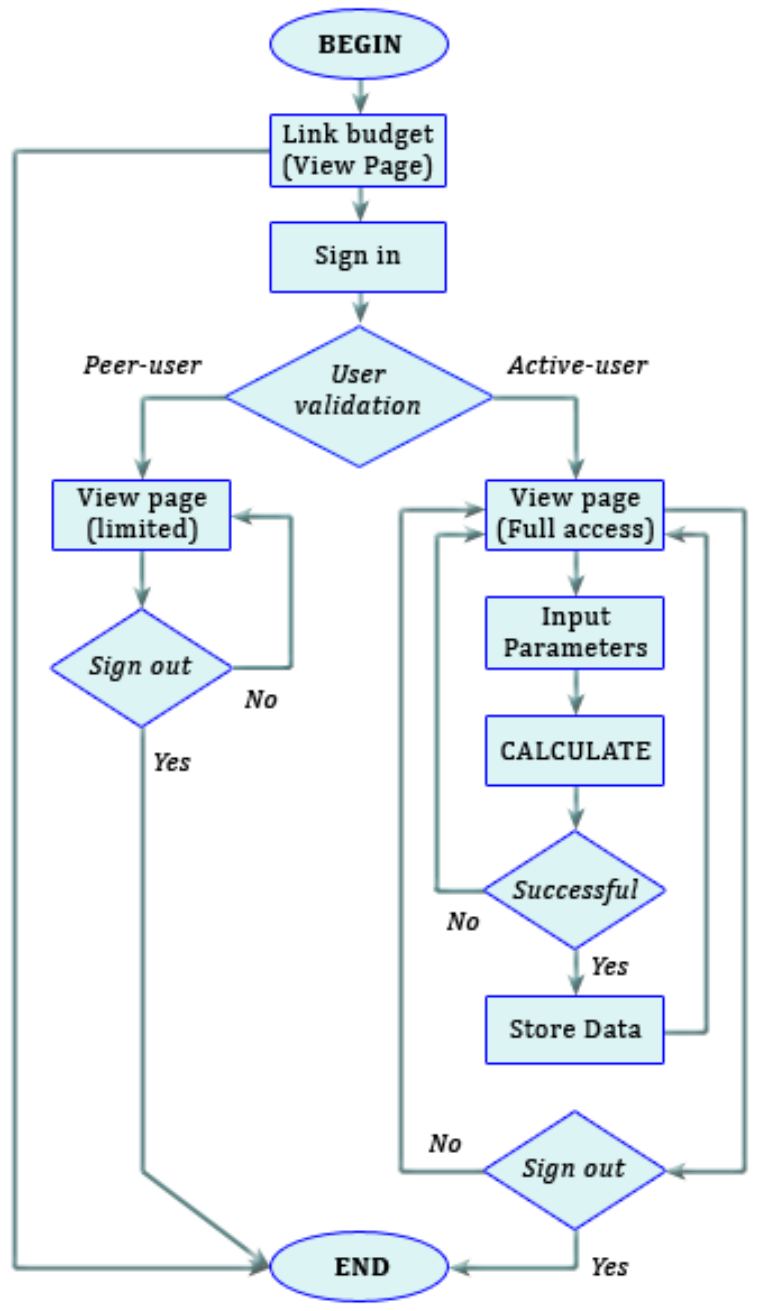

Figure 11: Process flow diagram of the designed Link Budget Tool for X-Band satellite communication

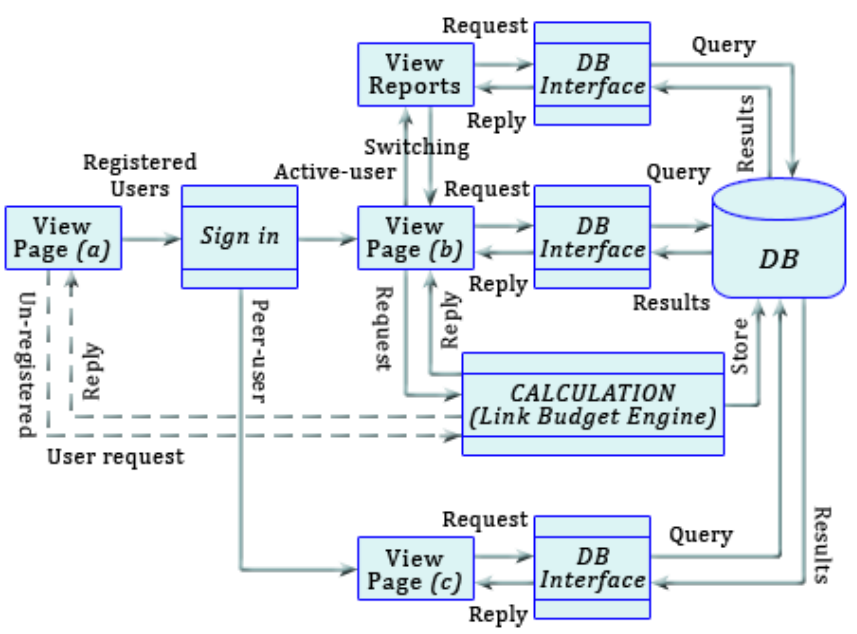

Figure 12: Data Flow Diagram (DFD) of the designed Link Budget Tool for X-band satellite communication

Detail data flow from user interfaces (view page) to Database (DB) through some processes are presented in the DFD (Figure 12). The calculation process is the Link Budget Engine (LBE) of the proposed web tool which can be accessed through View Page (a) of Unregistered users and View Page (b) of Active-users. After the process of any calculation, the LBE sends a request to DB for storing the data. The stored information can be retrieved by Activeusers (View Page (b)) and by Peer-users (View Page (c)) through DB Interface. It is to note that, View Page (c) has limited access comparing with the View Page (b) as explained in the Process Flow Diagram (PFD). Active-users can switch the View Page with View Reports to retrieve previous datasets and view usages history. At this stage, Active-user can update the user profile and create a Peeruser account.

The database schema, shown in Figure 13, is the logical view of the entire database of the proposed Link Budget tool. The schema presents the relational connectivity among seven entities. The entity "users" has one-to-many relations with other six entities, "transmitter", "receiver", "satellite", "rainatten_tx", "distance_tx", and "distance_r $x$ ". The "users" entity has a self-referential foreign key, "user_peerto", to maintain the hierarchy of Active-user and Peer-user. Basically, the Peer-user contains Active-user ID to indicate peer to that Active-user. On the other hand, Active-user may contain "NULL" for its self-referential foreign key as it is not a peer to itself. There is no weak entity in this schema.

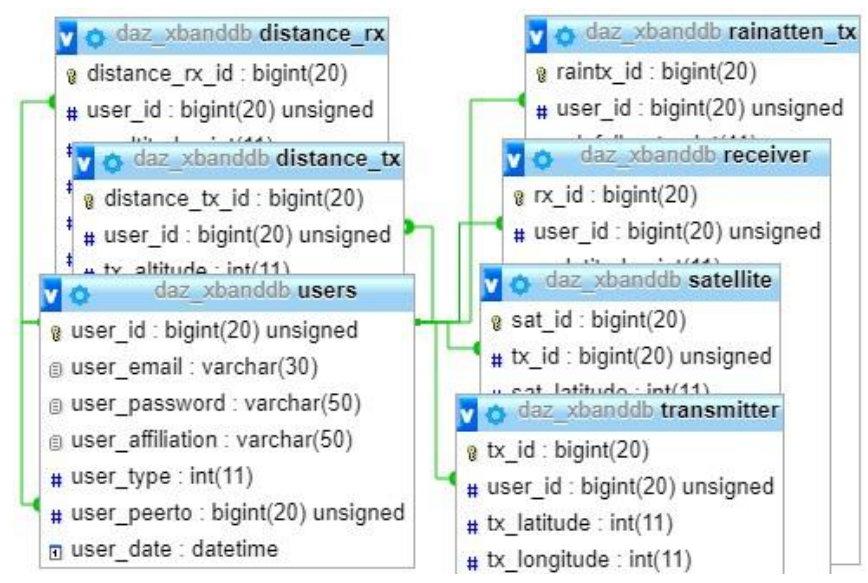

Figure 13: Database schema of the proposed web tool 


\section{B. User Interface of the Web Application Tool}

User interface for the active-user of the designed Link Budget Tool is presented in Figure 14. The interface has access to change input parameter values and calculate necessary output parameters on demand. The page is divided into six sections: TRANSMITTER $(T x)$ Earth Station, SATELLITE (Celestial Body), RECEIVER $(R x)$ Earth Station, DISTANCE $(T x)$, DISTANCE $(R x)$, and RAIN ATTENUATION. The "Calculate" button (found at the bottom of the page) can be used anytime if there is a change in input parameters and at the same time an Ajax request will be sent to the server without submitting the page which makes the system faster for calculation response. The "Reset" button (at the bottom of the interface) will help Active-users to set last updated data if necessary. At the top of the user interface, four navigation links exist through which users can perform some actions on demand. The links are: "HOME", "STATISTICS", "SIGN UP", and "SIGN IN". "HOME" links to the corresponding user home page. "SIGN $U P$ " and "SIGN IN" links are to register for new accounts and log in to the system, respectively. The link "SIGN IN" will change to "SIGN OUT" if any user is logged in the system. The navigation link "STATISTICS" will switch the user home interface to another page on which Active-user can access to the usage history, user profile (view and update), create new Peer, and update or delete existing peers.

The Peer-user interface (home page) will show limited information compare to the Active-user interface. The interface will present only the calculated parameter values. There will be no input option for changing input parameters as the user is a peer to the corresponding Active-user.

A Peer-user may be an Active-user if (s)he sign-up. Similarly, an Active-user may be a peer to another user if (s)he is chosen as a peer. In that case, the user will find a peer-list in "STATISTICS" page of the designed web tool.

\section{Features of the Web Application Tool}

In terms of design interfaces, the proposed link budget web tool is quite different compared to the other existing web tool found on the Internet. Other than calculating necessary parameters, the web tool provides some extra facilities and options for the users. The tool presents multiuser support, peer user concept, and usage history retrieval for future analysis if necessary. The following features can be highlighted for the designed web application tool.

- Necessary calculations on a single screen window

- Multiple types of user support (Registered (Activeuser \& Peer-user) and Unregistered users)

- The database is used in the back-end; thus, the tool can store user and usages data for future analysis if necessary

- $\quad$ No need a special setup like MATLAB, Visual Basic (VB), Spread sheet, etc. Just connect with the Internet and browse

- Unregistered users have instant access but no save or retrieve support

- Registered users have store and retrieve access, can create peer users, and view usages history

- Database admin can generate users and usages history reports

\section{Security Issues}

To ensure a secured web application tool, the most popular and secured MySQL database server is used with MySQLi database driver and Secure Hash Algorithm (SHA1) for encryption. While implementing, some other important issues are considered, like SQL injections, XSS (Cross-Site Scripting), Session management, Insecure Direct Object References (IDOR), Broken authentication, Exposing sensitive data, Security misconfiguration, Cross-Site Request Forgery (CSRF), and Input validation check.

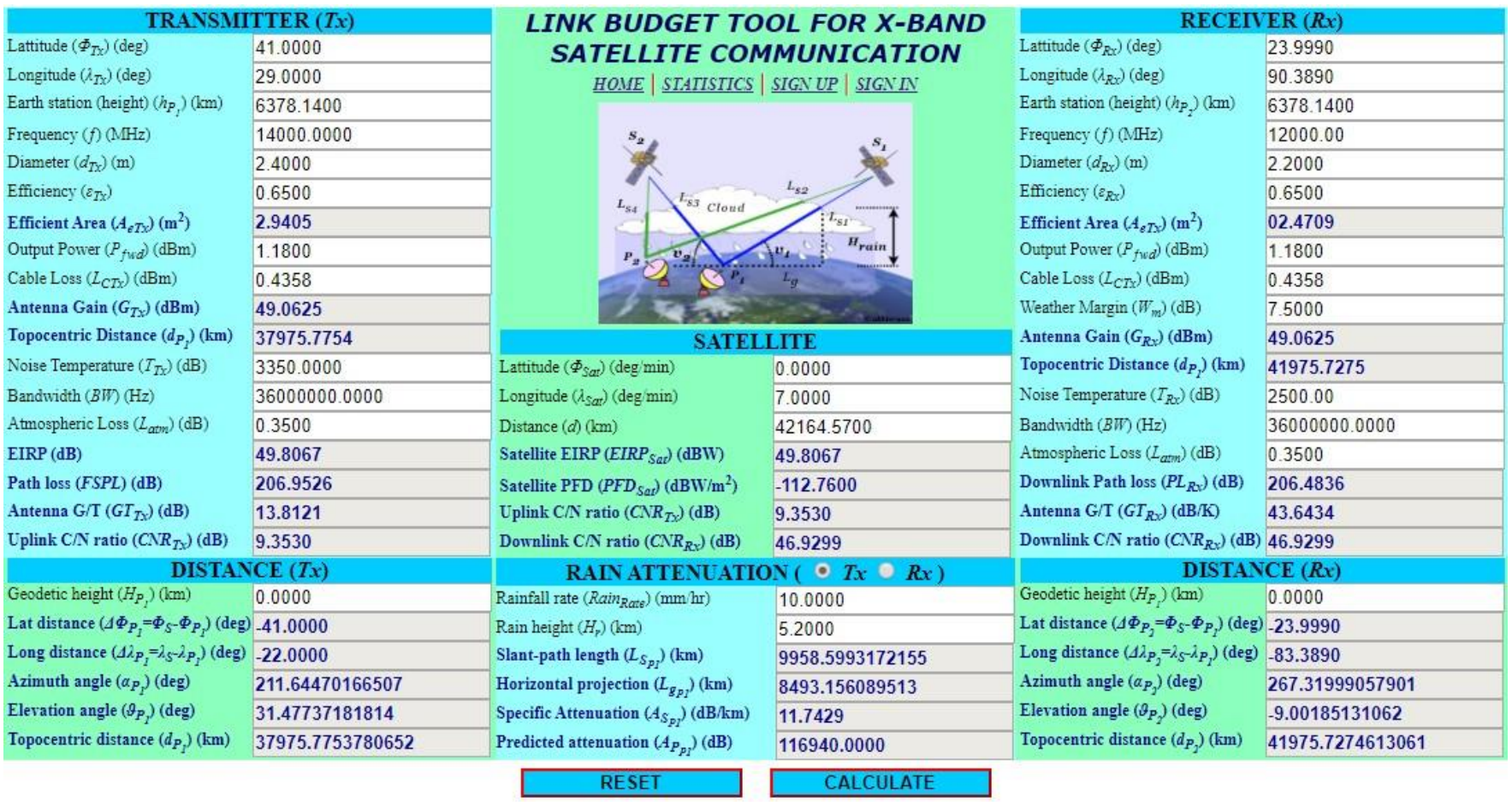

Figure 14: User interface of the proposed Link Budget Tool with six sections: TRANSMITTER (Tx) Earth Station, SATELLITE (Celestial Body), RECEIVER $(R x)$ Earth Station, DISTANCE $(T x)$, DISTANCE $(R x)$, and RAIN ATTENUATION (Tx and $R x)$. The highlighted texts and values are indicating the output parameters which cannot be changed while the un-highlighted texts and values are the input parameters that can be changed on demand. 


\section{COMPARATIVE ASSESSMENT AND RESULTS}

To evaluate the performance and validate the designed Link Budget web application tool, a comparative analysis is performed among various existing web tools and available functions of MATLAB. Results show that the applied methods are correct and viable to produce accurate results, although some minor errors are encountered. It is important to note that, not all the available web tools found on the Internet are producing the same results, there are some fluctuations in the results.

A comparative analysis is conducted focusing on some output parameters, such as: distance analysis (Topocentric distance, Azimuth angle, and Elevation angle), Uplink parameters, and Downlink parameters. For the actual error calculation, the minus ' - ' sign represents greater value and the plus ' + ' sign represents a smaller value of X-Band result than the results of compared web tools or functions. The ' $\%$ of error' (PoE) is calculated based on Equation (40).

PoE $=\frac{\text { Calculated value-Observed value }}{\text { Calculated value }} \times 100$

\section{A. Comparison of Distance Parameters}

To compare distance parameters, three important output parameters are chosen: Azimuth angle $(\alpha)$, Elevation angle $(\vartheta)$, and Topocentric distance $(d)$. Five existing web calculator tools are selected among which two web tools (Satcom Services Networks, 2020; and OMNI, 2020) present their calculation methods and equations. Three web tools (Cross, 2020; TutorialsWeb, 2020; and TRIAXMAN, 2020) do not describe any calculation methods or equations. Four different MATLAB functions are also chosen to compare and evaluate the performance of the designed X-Band web application tool. Table 2 presents the comparison results among selected and designed web tools and functions.

Calculation of $\alpha, \vartheta$, and $d$ depend on six input parameters: Latitude of earth station $\left(\phi_{P}\right)$, Longitude of earth station $\left(\lambda_{P}\right)$, Height of earth station $\left(h_{P}\right)$, Latitude of satellite $\left(\phi_{S}\right)$, Longitude of satellite $\left(\lambda_{S}\right)$, and Satellite orbital radius $\left(h_{S}\right)$. Satcom Services Networks (2020), TutorialsWeb (2020), and MATLAB functions $2 \& 3$ do not produce any results for Topocentric distance $(d)$. OMNI (2020) also does not produce Topocentric distance $(d)$, rather it produces distance on the Earth surface using Haversine formula. Results of Elevation angle $(\vartheta)$ was not found for OMNI (2020) and MATLAB function $2 \& 3$. All the chosen web tools and MATLAB functions produce results for Azimuth angle $(\alpha)$. For no output results, "Not a Number" ('NaN') is used as shown in Table 2.

The output of designed web tool (X-Band) for Topocentric distance $(d)$ shows the same result as produced in TRIAXMAN (2020), thus Percent of Error (PoE) is about $0.00 \%$. The result shows errors comparing with Cross (2020) (actual error $d_{e}=-2827.43 \mathrm{~km}$ and PoE is $-7.4454 \%$ ), and MATLAB functions $1 \& 4$ (actual error $d_{e}=-2664.68 \mathrm{~km}$ and $\mathrm{PoE}$ is $\left.-7.0168 \%\right)$.

In terms of the elevation angle $(\vartheta)$, the X-Band result shows an exact match with the outputs of MATLAB functions $1 \&$ 4. Results compared with other web tools show some errors; actual errors $+0.1366^{\circ}(+0.4340 \%), \quad+0.9911^{\circ}$ $(+3.1486 \%),-6.0153^{\circ}(-19.1100 \%)$, and $-6.0826^{\circ}$
$(-19.3240 \%)$ are found for Satcom Services Networks (2020), Cross (2020), TutorialsWeb (2020), and TRIAXMAN (2020) respectively.

PoE of Azimuth angle $(\alpha)$ is found as $0.00 \%$ for MATLAB function 1 which indicates the same output values (no actual error). The result $(\alpha)$ of X-Band compared with three web tools (Satcom Services Networks, 2020; OMNI, 2020; and TRIAXMAN, 2020) shows identical PoE $(+0.0082 \%)$ as the calculated values show same actual errors $\left(\alpha_{e}=\right.$ $+0.0174)$. MATLAB functions $2 \& 4$ show actual errors as $+0.0184^{\circ}$ and $-0.1209^{\circ}$, respectively; producing $\mathrm{PoE}$ as $+0.0087 \%$ and $-0.0571 \%$ individually. MATLAB function 3 does not produce 'Great Circle track value', rather it produces 'Rhumb Line track value'. This raise demands further analysis of these two concepts in designing the Link Budget web application tool.

Scrutinizing results shows that the outputs of $d, \alpha$, and $\vartheta$ produced by X-Band web tool are accurate in most of the cases, although there exist some little fluctuations of errors. The bigger errors found in some comparisons reflect that further study and analysis are needed for those corresponding web tools as any authenticated methods or equations are not found from their websites.

Results of Azimuth angle $(\alpha)$, Elevation angle $(\vartheta)$, and Topocentric distance $(d)$ are simulated for the variations of Longitude of a celestial body (Satellite $\lambda_{S}$ ) ranging from $5.00^{\circ}$ to $53.00^{\circ}$ as presented in Figure 15 , Figure 16 , and Figure 17. Changes in the of Azimuth angle show almost linearly decreasing characteristics (Figure 15). This is because of the chosen coordinates of the Earth station and Satellite. Variation of longitude reflects the movements of the Satellite on the Equator plane as the latitude is $0.00^{\circ}$, while the position of Earth station is at the North side of the Equator $\left(41.00^{\circ} \mathrm{N} 29.00^{\circ} \mathrm{E}\right)$. With the reference point of the chosen Earth station, the Satellite is moving from West to East, thus the changes of Azimuth angle show decreasing characteristics.

The behavior of Elevation angle $(\vartheta)$ changes with the variation of Satellite longitude $\left(\lambda_{S}\right)$ is presented in Figure 16 where dome shape characteristics are observed. This is because, when the Satellite is orbiting from West to East on the Equator plane, with the reference tangent plane of Earth station, the height of the Satellite is increasing till the longitude of $29.00^{\circ} \mathrm{E}$ and then decreasing, thus Elevation angle (look angle) shows increasing and decreasing behavior creating the dome shape characteristics. Results of compared web tools and MATLAB functions follow the same behavior pattern while the Satcom Services Networks (2020) results produce dome shape behavior but follow different path. Further analysis is necessary to explain this different characteristic.

Changes of Satellite positions from $5.00^{\circ} \mathrm{E}$ to $29.00^{\circ} \mathrm{E}$ reduces the Topocentric distance $(d)$ as it reached to its shortest distance at this point. After that, the distance is increasing to $53.00^{\circ} \mathrm{E}$. Thus, the variations of $d$ show about boat shape characteristics as presented in Figure 17. Results of compared tools and functions show similar characteristics while the results calculated in OMNI (2020) are little far from the other because it presents distance on Earth surface by using Haversine formula, not the Topocentric distance in between Satellite and Earth station. 
Table 2

Comparison of Azimuth angle $(\alpha)$, Elevation angle ( $\vartheta$ ), and Topocentric distance (d) among various methods and web tools (Satcom Services Networks, 2020; OMNI, 2020; Cross, 2020; TutorialsWeb, 2020; TRIAXMAN, 2020).

\begin{tabular}{|c|c|c|c|}
\hline $\begin{array}{c}\text { INPUT } \\
\text { PARAMETERS }\end{array}$ & $\begin{array}{c}\text { REFERENCES } \\
\& \\
\text { USED EQUATIONS OR FUNCTIONS }\end{array}$ & RESULTS & $\begin{array}{l}\text { ACTUAL } \\
\text { ERRORS }\end{array}$ \\
\hline & $\begin{array}{l}\text { Satcom Services Networks (2020): } \\
\begin{array}{l}\alpha=180+\tan ^{-1}\left(\frac{\tan \left(\lambda_{P}-\lambda_{S}\right)}{\sin \left(\phi_{P}\right)}\right) \\
\vartheta=\tan ^{-1}\left(\frac{\mu^{2}+\left(h_{p}\right)^{2}-\left(h_{s}\right)^{2}}{2 \mu h_{p}}\right) \\
\mu=\left(\left(h_{p}\right)^{2}+\left(h_{s}\right)^{2}-2 h_{p} h_{s} \cos \phi_{p} \cos \left(\lambda_{p}-\lambda_{s}\right)\right)^{1 / 2} \\
d=\text { Not available }\end{array}\end{array}$ & $\begin{array}{c}\alpha=211.6300^{\circ} \\
\vartheta=031.3408^{\circ} \\
d=N a N\end{array}$ & $\begin{array}{c}\alpha_{e}=+0.0174^{\circ} \\
\vartheta_{e}=+0.1366^{\circ} \\
d_{e}=N a N\end{array}$ \\
\hline $\begin{array}{c}\text { Earth Station }\left(P_{1}\right) \\
\text { Latitude }\end{array}$ & $\begin{array}{l}\text { OMNI (2020): } \\
\alpha=\tan ^{-1}\left(\frac{\left(\sin \left(\lambda_{S}-\lambda_{P}\right) \cos \phi_{S}\right)}{\left(\cos \phi_{P} \sin \phi_{S}-\sin \phi_{P} \cos \phi_{S} \cos \left(\lambda_{S}-\lambda_{P}\right)\right)}\right) \\
\vartheta=N o t \text { Available } \\
\text { Haversine formula (use radian): } \\
\text { Distance }\left(d_{E}\right) \text { on the Earth surface. } \\
d=a\left(2 \tan ^{-1}\left(\frac{\sqrt{q}}{\sqrt{1-q}}\right)\right) \\
q=\sin ^{2}\left(\frac{\left(\phi_{S}-\phi_{p}\right)}{2}\right)+\cos \phi_{p} \cos \phi_{S} \sin ^{2}\left(\frac{\lambda_{S}-\lambda_{p}}{2}\right)\end{array}$ & $\begin{array}{c}\alpha=211.6300^{\circ} \\
\vartheta=N a N \\
d=N a N \\
d_{E}=5070.00 \mathrm{~km}\end{array}$ & $\begin{array}{c}\alpha_{e}=+0.0174^{\circ} \\
\vartheta_{e}=N a N \\
\quad d_{e}=N a N \\
d_{E e} \\
=+32905.78 \mathrm{~km}\end{array}$ \\
\hline $\begin{array}{l}\phi_{P}=41.0^{\circ} \\
\text { Longitude } \\
\lambda_{P}=29.0^{\circ}\end{array}$ & $\begin{array}{l}\text { Cross (2020): } \\
\text { Equations are not available. }\end{array}$ & $\begin{array}{c}\alpha=211.2183^{\circ} \\
\vartheta=30.4863^{\circ} \\
d=40803.21 \mathrm{~km}\end{array}$ & $\begin{array}{c}\alpha_{e}=+0.4264^{\circ} \\
\vartheta_{e}=+0.9911^{\circ} \\
d_{e}=-2827.43 \mathrm{~km}\end{array}$ \\
\hline $\begin{array}{c}\text { Earth Radius } \\
h_{P}=6378.14 \mathrm{~km}\end{array}$ & $\begin{array}{l}\text { TutorialsWeb (2020): } \\
\text { Equations are not available. }\end{array}$ & $\begin{array}{c}\alpha=211.6165^{\circ} \\
\vartheta=037.4927^{\circ} \\
d=N a N\end{array}$ & $\begin{array}{c}\alpha_{e}=+0.0282^{\circ} \\
\vartheta_{e}=-6.0153^{\circ} \\
d_{e}=N a N\end{array}$ \\
\hline & $\begin{array}{l}\text { TRIAXMAN (2020): } \\
\text { Equations are not available. }\end{array}$ & $\begin{array}{c}\alpha=211.6300^{\circ} \\
\vartheta=037.5600^{\circ} \\
d=37975.36 \mathrm{~km}\end{array}$ & $\begin{array}{c}\alpha_{e}=+0.0174^{\circ} \\
\vartheta_{e}=-6.0826^{\circ} \\
d_{e}=0000.42 \mathrm{~km}\end{array}$ \\
\hline $\begin{array}{c}\text { Satellite (S) } \\
\text { Latitude } \\
\phi_{S}=0.0^{\circ}\end{array}$ & $\begin{array}{l}\text { MATLAB Function 1: } \\
\text { wgs84 = wgs84Ellipsoid('kilometer'); } \\
{[e, n, u]=\operatorname{geodetic2enu}\left(\phi_{S}, \lambda_{S}, h_{S}, \phi_{P}, \lambda_{P}, h_{P}, \text { wgs } 84\right) ;} \\
{[\alpha, \vartheta, d]=\operatorname{enu} 2 \operatorname{aer}(e, n, u) ;} \\
\text { OR } \\
{[\alpha, \vartheta, d]=\text { geodetic2aer }\left(\phi_{S}, \lambda_{S}, h_{S}, \phi_{P}, \lambda_{P}, h_{P}, \text { wgs84); }\right.}\end{array}$ & $\begin{array}{c}\alpha=211.6447^{\circ} \\
\vartheta=031.4774^{\circ} \\
d=40640.46 \mathrm{~km}\end{array}$ & $\begin{array}{c}\alpha_{e}=0.0000^{\circ} \\
\vartheta_{e}=0.0000^{\circ} \\
d_{e}=-2664.68 \mathrm{~km}\end{array}$ \\
\hline $\begin{array}{l}\text { Longitude } \\
\lambda_{S}=7.0^{\circ}\end{array}$ & $\begin{array}{l}\text { MATLAB Function 2: } \\
\% \text { 'gc' (Great Circle) track value... } \\
\left.\alpha=\text { azimuth ('gc', } \phi_{P}, \lambda_{P}, \phi_{S}, \lambda_{S}\right) ;\end{array}$ & $\begin{array}{c}\alpha=211.6263^{\circ} \\
\vartheta=N a N \\
d=N a N\end{array}$ & $\begin{array}{c}\alpha_{e}=+0.0184^{\circ} \\
\vartheta_{e}=N a N \\
d_{e}=N a N\end{array}$ \\
\hline \multirow{3}{*}{$\begin{array}{c}\text { Orbital Radius } \\
h_{S}=42164.57 \mathrm{~km}\end{array}$} & $\begin{array}{l}\text { MATLAB Function 3: } \\
\% \text { 'rh' (Rhumb Line) track value... } \\
\left.\alpha=\text { azimuth('rh', } \phi_{P}, \lambda_{P}, \phi_{S}, \lambda_{S}\right)\end{array}$ & $\begin{array}{c}\alpha=206.0401^{\circ} \\
\vartheta=N a N \\
d=N a N\end{array}$ & $\begin{array}{c}\alpha_{e}=+5.5866^{\circ} \\
\vartheta_{e}=N a N \\
d_{e}=N a N\end{array}$ \\
\hline & $\begin{array}{l}\text { MATLAB Function 4: } \\
\text { \% Available at MATLAB } R 2013 a \ldots\left(h_{p}=h_{s}=\text { meters }\right) \\
{[\vartheta, d, \alpha]=\text { elevation }\left(\phi_{p}, \lambda_{P}, h_{P}, \phi_{S}, \lambda_{S}, h_{S}\right)}\end{array}$ & $\begin{array}{c}\alpha=211.7656^{\circ} \\
\vartheta=031.4774^{\circ} \\
d=40640.46 \mathrm{~km}\end{array}$ & $\begin{array}{c}\alpha_{e}=-0.1209^{\circ} \\
\vartheta_{e}=+0.0000^{\circ} \\
d_{e}=-2664.68 \mathrm{~km}\end{array}$ \\
\hline & 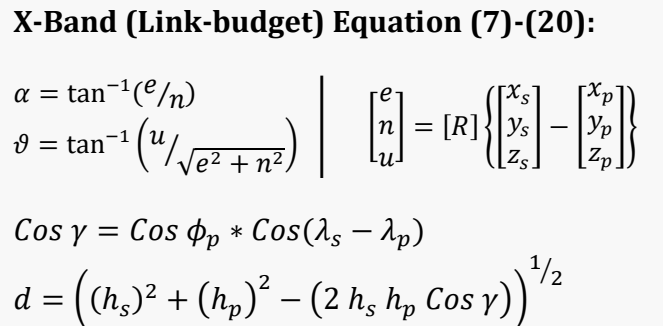 & $\begin{array}{c}\alpha=211.6447^{\circ} \\
\vartheta=031.4774^{\circ} \\
d=37975.78 \mathrm{~km}\end{array}$ & $\begin{array}{c}\alpha_{e}=0.00^{\circ} \\
\vartheta_{e}=0.00^{\circ} \\
d_{e}=0.00 \mathrm{~km}\end{array}$ \\
\hline
\end{tabular}

Note: Values in the table are obtained from direct outputs of the reference webtools, simulated MATLAB Functions 1 to 4 , and Implemented $X$-Band (Link-budget) equations. Errors are determined by comparing the obtained values with the results of the proposed Link-budget Web Tool for X-Band Satellite Communication. 


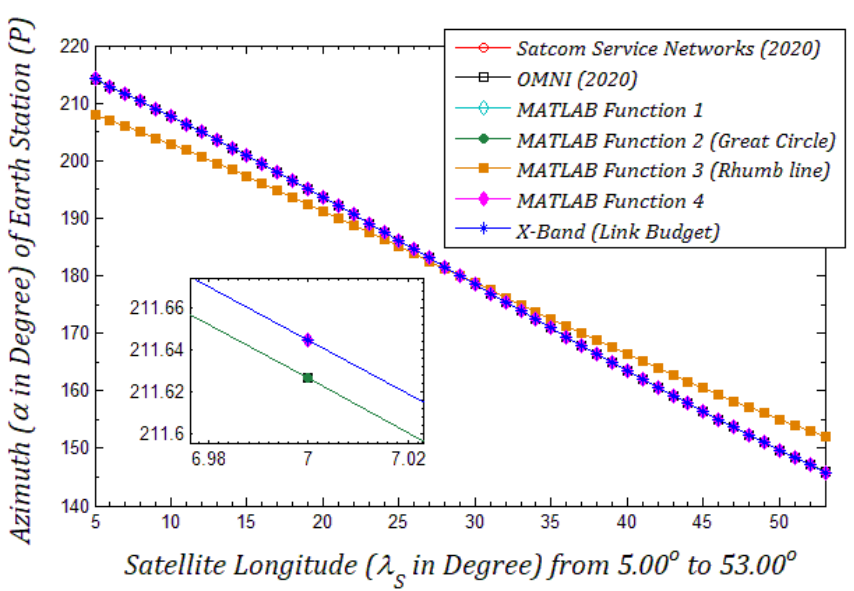

Figure 15: Changes of Azimuth angle $(\alpha)$ with the variation of Satellite longitude $\left(\lambda_{S}\right)$

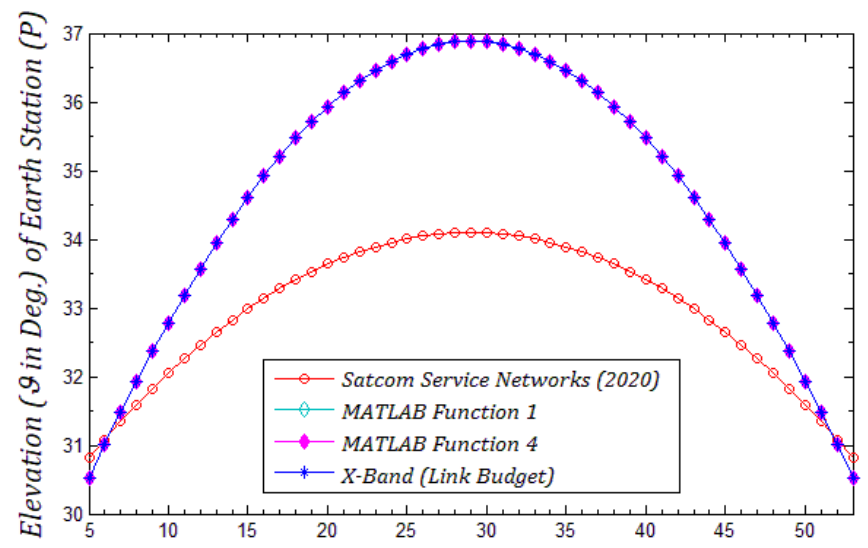

Satellite Longitude $\left(\lambda_{S}\right.$ in Degree) from $5.00^{\circ}$ to $53.00^{\circ}$

Figure 16: Behavior of Elevation angle $(\vartheta)$ changes for the variations of Satellite longitude $\left(\lambda_{S}\right)$

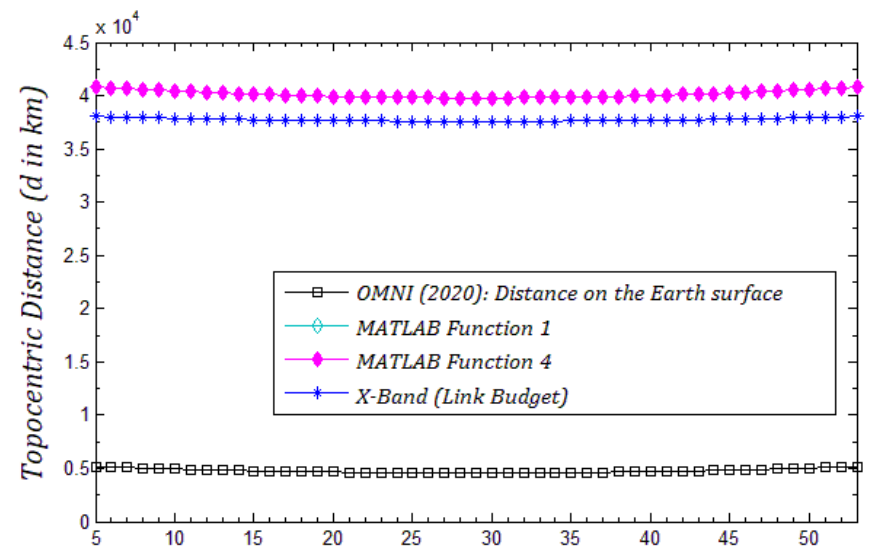

Satellite Longitude ( $\lambda_{s}$ in Degree) from $5.00^{\circ}$ to $53.00^{\circ}$

Figure 17: Characteristics of Topocentric distance $(d)$ variations with the changes of Satellite longitude $\left(\lambda_{S}\right)$

\section{B. Comparison of Uplink Parameters}

Comparison of Uplink parameters include Efficient area of transmitter antenna $\left(A_{e T x}\right)$, Antenna Gain $\left(G_{T x}\right)$, Effective Isotropic Radiated Power (EIRP), Free Space Path Loss (FSPL), Antenna G/T $\left(G T_{T x}\right)$, Career to Noise Ratio (CNR), and Satellite Power Flex Density (PFD). Results of X-Band are compared with five available Web Tools found on the Internet, which are: Satcom Services Networks (2020), SWA (2020), everithingRF (2015), Johnston (2019), and SatcomUK (2015). Comparison results are presented in
Table 3 which indicates that not all results can be generated from the available online tools comparing with the results of the proposed X-Band Link Budget tool.

Outputs of $A_{e T x}$ are not generated by any of the selected web tools. Satcom Services Networks (2020) does not produce any output for PFD. SWA (2020) does not have $G_{T x}, G T_{T x}$, CNR, and PFD calculators. The results of $G T_{T x}, \mathrm{CNR}$, and PFD are also not found in everithingRF (2015).

Table 3

Comparison of Uplink Parameters among various web tools (Satcom Services Networks, 2020; SWA, 2020; EverithingRF, 2015; Johnston, 2019, SatcomUK, 2015)

\begin{tabular}{|c|c|c|}
\hline $\begin{array}{l}\text { REFERENCES \& } \\
\text { USED EQUATIONS }\end{array}$ & OUTPUT & $\begin{array}{l}\text { ACTUAL } \\
\text { ERRORS }\end{array}$ \\
\hline \multicolumn{3}{|l|}{ Satcom Services Networks (2020): } \\
\hline $\begin{aligned} G_{T x}= & 10 \log _{10}\left(\varepsilon_{T x}\right)+20 \log _{10}\left(f d_{T x}\right) \\
& +(-159.59)\end{aligned}$ & $049.0659 d B$ & $-00.0030 d B$ \\
\hline$E I R P=10 \log _{10}\left(P_{T x}\right)+G_{T x}$ & $049.7847 d B$ & $-00.0010 d B$ \\
\hline $\begin{array}{l}F S P L=20 \log _{10}(f d)+92.5 \\
(\text { f is } 14 \mathrm{GHz})\end{array}$ & $207.0127 d B$ & $-00.0601 d B$ \\
\hline$G T_{T X}=G_{T x}-10 \log _{10}\left(T_{T x}\right)$ & $013.8155 d B$ & $-00.0034 d B$ \\
\hline$C N R=\begin{array}{l}E I R P-F S P L+G T_{T x}- \\
10 \log _{10}(B W)-k_{\text {bolt }}-L_{\text {atm }}\end{array}$ & $009.2745 d B$ & $+00.0785 d B$ \\
\hline \multicolumn{3}{|l|}{ SWA (2020): } \\
\hline$E I R P=P_{T x}-L_{C T x}+G_{T x}$ & $049.8067 d B$ & $00.0000 d B$ \\
\hline $\begin{array}{l}F S P L=20 \log _{10}(4 \pi d f / c)-G_{T x}-G_{R x} \\
(\text { d in meter })\end{array}$ & $108.8355 d B$ & $+98.1171 d B$ \\
\hline \multicolumn{3}{|c|}{ everithingRF (2015): (Parabolic Antenna Gain) } \\
\hline$G_{T x}=10 \log _{10}\left(k\left(\pi d_{T x} / \tilde{\lambda}\right)^{2}\right)$ & $049.0625 \mathrm{~dB}$ & $00.0000 d B$ \\
\hline$E I R P=P_{T x}-L_{C T x}+G_{T x}$ & $049.8067 d B$ & $00.0000 d B$ \\
\hline $\begin{array}{l}F S P L=20 \log _{10}(4 \pi d f / c)-G_{T x}-G_{R x} \\
(\text { d in meter })\end{array}$ & $108.8355 d B$ & $+98.1171 d B$ \\
\hline \multicolumn{3}{|l|}{ Johnston (2019): } \\
\hline$G_{T x}$ & $049.0565 d B$ & $+00.0060 \mathrm{~dB}$ \\
\hline EIRP & $049.7753 d B$ & $+00.0314 d B$ \\
\hline FSPL & $206.9627 d B$ & $-00.0101 d B$ \\
\hline$G T_{T x}$ (as input) & $013.8121 d B$ & $00.0000 d B$ \\
\hline CNR & $009.6616 d B$ & $-00.3086 d B$ \\
\hline$P F D$ & $-112.82 d B W m^{-2}$ & $+00.04 \mathrm{dBW} \mathrm{m}^{2}$ \\
\hline \multicolumn{3}{|l|}{ SatcomUK (2015): } \\
\hline$G_{T x}$ & $049.0600 \mathrm{~dB}$ & $+00.0025 d B$ \\
\hline$E I R P$ & $050.2400 d B$ & $-00.4333 d B$ \\
\hline$F S P L$ & $207.1600 d B$ & $-00.2074 d B$ \\
\hline$G T_{T x}$ (as input) & $013.8121 d B$ & $00.0000 d B$ \\
\hline$C N R$ & $009.9400 d B$ & $-00.5870 d B$ \\
\hline$P F D$ & $-112.52 d B W m^{-2}$ & $-00.26 d B W m^{2}$ \\
\hline \multicolumn{3}{|l|}{ X-Band (Link-budget): } \\
\hline$A_{e T x}=\pi\left(r_{T x}\right)^{2} \varepsilon_{T x}$ & $002.9405 \mathrm{~m}^{2}$ & $00.0000 \mathrm{~m}^{2}$ \\
\hline$G_{T x}=10 \log _{10}\left(\varepsilon_{T x}\left(\pi d_{T x} / \tilde{\lambda}\right)^{2}\right)$ & $049.0625 \mathrm{~dB}$ & $00.0000 d B$ \\
\hline$E I R P=G_{T x}+P_{T x}-L_{C T x}$ & $049.8067 d B$ & $00.0000 d B$ \\
\hline $\begin{array}{l}F S P L=20 \log _{10}(f d)+32.44 \\
(f \text { in } G H z \text { \& d in meter })\end{array}$ & $206.9526 d B$ & $00.0000 d B$ \\
\hline$G T_{T X}=G_{T X}-10 \log _{10}\left(T_{T X}\right)$ & $013.8121 d B$ & $00.0000 d B$ \\
\hline $\begin{aligned} C N R= & E I R P-F S P L-10 \log _{10}(b w) \\
& +G T_{T x}-L_{a t m}-k_{\text {bolt }}\end{aligned}$ & $009.3530 d B$ & $00.0000 d B$ \\
\hline$P F D=E I R P-10 \log _{10}\left(4 \pi d^{2}\right)$ & $-112.76 \mathrm{dBWm^{2 }}$ & $0.00 \mathrm{dBW} \mathrm{m}^{2}$ \\
\hline
\end{tabular}


All the output parameters except Gain $\left(G_{T x}\right)$ can be calculated in Johnston (2019) and SatcomUK (2015). Related input parameters with relevant values are presented in Table 4. Based on the results found in Table 3, PoEs are calculated and presented graphically in Figure 18.

Table 4

Uplink input parameter values for necessary calculations

\begin{tabular}{ll}
\hline \hline \multicolumn{1}{c}{ PARAMETERS } & \multicolumn{1}{c}{ VALUES } \\
\hline Speed of radio wave & $c=299792458 \mathrm{~ms}^{-1}$ \\
Frequency & $f=14 \times 10^{9} \mathrm{~Hz}$ \\
Antenna diameter & $d_{T x}=2.4 \mathrm{~m}$ \\
Wavelength & $\tilde{\lambda}={ }^{c} / f=0.021413747 \mathrm{~m}$ \\
Antenna or Aperture efficiency & $\varepsilon_{T x}=k=0.65=65 \%$ \\
Efficient area of antenna & $A_{\text {eTx }}=02.9405 \mathrm{~m}^{2}$ \\
Transmitter output power & $P_{T x}=1.18 \mathrm{dBm}$ \\
Cable loss & $L_{C T x}=0.4358 \mathrm{dBm}$ \\
Antenna gain & $G_{T x}=G_{R x}=49.0625 \mathrm{dBm}$ \\
Topocentric distance & $d_{P_{1}}=37975.7754 \mathrm{~km}$ \\
System noise temperature & $T_{T x}=3.350 \times 10^{3} \mathrm{~dB}$ \\
Bandwidth & $B W=36 \times 10^{6} \mathrm{~Hz}$ \\
Boltzmann constant & $k_{\text {bolt }}=-228.6$ \\
Atmospheric loss & $L_{a t m}=0.35 \mathrm{~dB}$ \\
\hline \hline
\end{tabular}

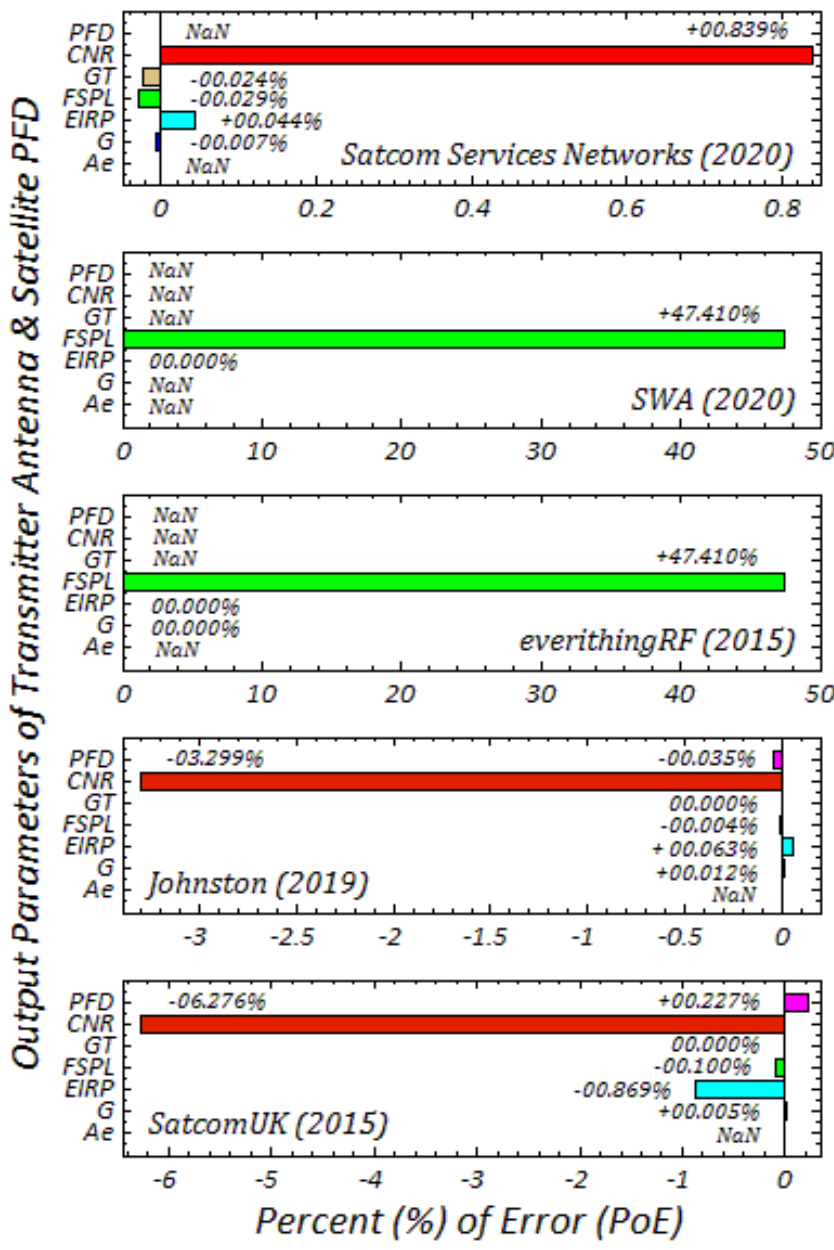

Figure 18: Output parameters of a transmitter antenna and Satellite PFD vs. Percent (\%) of Error (PoE) of various web tools compared with the proposed Link-budget tool
Johnston (2019) and SatcomUK (2015) do not provide any used methods or equations of their calculations. The other three web tools present the necessary calculation methods. Results of SWA (2020) and everithingRF (2015) show highest PoE $(+47.4100 \%)$ for FSPL as both of them use same equations with a little variation than the equation used in the proposed Link Budget tool. This issue must be considered in future study to validate the presented equation. Other results reflect very minor fluctuation in results with very little PoE as shown in Figure 18, confirming viability of designed Link Budget web tool. ' $\mathrm{NaN}$ ' in the figure indicates 'Not a Number' for unavailable results.

\section{Comparison of Downlink Parameters}

Five output parameters are considered to evaluate downlink parameter results performances of the proposed X-Band Link Budget tool, as presented in Table 5. The selected parameters are: Effective area of receiver antenna $\left(A_{e R x}\right)$, Antenna gain $\left(G_{R x}\right)$, Antenna G/T $\left(G T_{R x}\right)$, Path loss $\left(P L_{R x}\right)$, and Downlink Career to Noise Ratio $(C N R)$.

\section{Table 5}

Comparison of Downlink Parameters among various web tools (Satcom Services Networks, 2020; everithingRF, 2015; Johnston, 2019; SatcomUK, 2015)

\begin{tabular}{|c|c|c|}
\hline $\begin{array}{l}\text { REFERENCES \& } \\
\text { USED EQUATIONS }\end{array}$ & OUTPUT & $\begin{array}{l}\text { ACTUAL } \\
\text { ERRORS }\end{array}$ \\
\hline \multicolumn{3}{|l|}{ Satcom Services Networks (2020): } \\
\hline $\begin{array}{l}G_{R x}=\begin{array}{l}10 \log _{10}\left(\varepsilon_{R x}\right)+20 \log _{10}\left(f d_{R x}\right) \\
+(-159.59)\end{array} \\
\text { [Note: corrected equation] }\end{array}$ & $046.9600 d B$ & $+00.0078 d B$ \\
\hline$G T_{R X}=G_{R x}-10 \log _{10}\left(T_{R x}\right)$ & $043.6400 d B$ & $+00.0034 d B$ \\
\hline $\begin{array}{l}P L_{R x}=20 \log _{10}(f d)+92.5 \\
(\rightarrow f \text { is } 12 \mathrm{GHz})\end{array}$ & $206.5400 d B$ & $-00.0561 d B$ \\
\hline $\begin{aligned} C N R= & E I R P_{S}-10 \log _{10}(b w)-P L_{R x} \\
& +G T_{R x}-k_{\text {bolt }}-L_{a t m}\end{aligned}$ & $039.5900 d B$ & $+07.3399 d B$ \\
\hline \multicolumn{3}{|c|}{ everithingRF (2015): (Parabolic Antenna Gain) } \\
\hline$G_{R x}=10 \log _{10}\left(k\left(\pi d_{R x} / \tilde{\lambda}\right)^{2}\right)$ & $046.9678 d B$ & $00.0000 d B$ \\
\hline $\begin{array}{l}P L_{R x}=20 \log _{10}(4 \pi d f / c) \\
(\rightarrow d \text { in meter })\end{array}$ & $206.4914 d B$ & $-00.0078 d B$ \\
\hline \multicolumn{3}{|l|}{ Johnston (2019): } \\
\hline$G_{R x}$ & $046.9618 d B$ & $+00.0060 d B$ \\
\hline$G T_{R x}$ & $043.6374 d B$ & $+00.0334 d B$ \\
\hline$P L_{R x}$ & $205.6238 d B$ & $+00.8598 d B$ \\
\hline$C N R$ & $040.8573 d B$ & $+06.0726 d B$ \\
\hline \multicolumn{3}{|l|}{ SatcomUK (2015): } \\
\hline$G_{R x}$ & $046.9600 d B$ & $+00.0078 d B$ \\
\hline$G T_{R x}$ & $043.6100 d B$ & $+00.0334 d B$ \\
\hline$P L_{R x}$ & $206.4900 d B$ & $-00.0064 d B$ \\
\hline CNR & $046.9300 d B$ & $-00.0001 d B$ \\
\hline \multicolumn{3}{|l|}{ X-Band (Link-budget): } \\
\hline$A_{e R x}=\pi\left(r_{R x}\right)^{2} \varepsilon_{R x}$ & $002.4709 d B$ & $00.0000 d B$ \\
\hline$G_{R x}=10 \log _{10}\left(\varepsilon_{R x}\left(\pi d_{R x} / \tilde{\lambda}\right)^{2}\right)$ & $046.9678 d B$ & $00.0000 d B$ \\
\hline$G T_{R X}=G_{R x}-10 \log _{10}\left(T_{R x}\right)$ & $043.6434 d B$ & $00.0000 d B$ \\
\hline $\begin{array}{l}P L_{R x}=20 \log _{10}\left(4 \pi f d_{P_{2} / C}\right) \\
\left(\rightarrow f \text { in } G H z \& d_{P_{2}} \text { in meter }\right)\end{array}$ & $206.4836 d B$ & $00.0000 d B$ \\
\hline$C N R=\begin{array}{ll}E I R P_{S}-P L_{R x}-10 \log _{10}(b w)- \\
\\
L_{C R x}+G T_{R x}-k_{\text {bolt }}+W_{m}-L_{a t m}\end{array}$ & $046.9299 d B$ & $00.0000 d B$ \\
\hline
\end{tabular}


To conduct a comparative analysis, four existing web tools are chosen depending on the availability of the targeted output parameters. The available web tools are: Satcom Services Networks (2020), everithingRF (2015), Johnston (2019), and SatcomUK (2015).

Results presented in Table 5 show that only $G_{R x}$ and $P L_{R x}$ calculators are available in everithingRF (2015). Rest of the web tools have the functionality to produce results of output parameters except the parameter $A_{e R x}$. Satcom Services Networks (2020) and everithingRF (2015) provides necessary methods to calculate output parameters, while the other two web tools do not present any equation or method. Necessary input parameters with corresponding values are presented in Table 6.

Actual errors presented in Table 5 reflect that most of the errors are 0.00 or very close to 0.00 , which proofs that the proposed X-Band Link Budget tool produces accurate results for downlink parameter calculations. This also can be confirmed form graphical representation of PoEs as shown in Figure 19.

A little deflection is identified for the PoE results of CNR produced by Satcom Services networks (2020) and Johnston (2019) as $+15.6401 \%$ and $+12.9397 \%$, respectively. This issue must keep in mind in future studies.

\section{Overall Comments}

Based on the comparative assessments, the overall comment is that the three existing web tools found reliable in terms of output parameters and results. The three web tools are: Satcom Services Networks (2020), Johnston (2019), and SatcomUK (2015). The proposed X-Band Link Budget web tool produces reliable outputs reflecting very little PoEs and viable for practical uses.

Table 6

Downlink input parameters to calculate relevant output parameter values

\begin{tabular}{ll}
\hline \multicolumn{1}{c}{ PARAMETERS } & \multicolumn{1}{c}{ VALUES } \\
\hline Speed of radio wave & $c=299792458 \mathrm{~ms}^{-1}$ \\
Frequency & $f=12 \times 10^{9} \mathrm{~Hz}$ \\
Antenna diameter & $d_{R x}=2.2 \mathrm{~m}$ \\
Wavelength & $\tilde{\lambda}={ }^{c} / f=0.021413747 \mathrm{~m}$ \\
Rx Latitude & $\phi_{P_{2}}=23.9990^{\circ}$ \\
Rx Longitude & $\lambda_{P_{2}}=90.3890^{\circ}$ \\
Rx height (Earth Radius) & $h_{P_{2}}=6378.1400 \mathrm{~km}$ \\
Antenna or Aperture efficiency & $\varepsilon_{R x}=k=0.65=65 \%$ \\
Efficient area of antenna & $A_{e R x}=02.4709 \mathrm{~m}^{2}$ \\
Cable loss & $L_{C R x}=0.2235 \mathrm{dBm}$ \\
Weather Margin & $W_{m}=7.5 \mathrm{~dB}$ \\
Satellite EIRP & $E I R P_{S}=49.8067$ \\
Antenna gain & $G_{R x}=49.0625 \mathrm{dBm}$ \\
Topocentric distance & $d_{P_{2}}=41975.7275 \mathrm{~km}$ \\
System noise temperature & $T_{R x}=2.15 \times 10^{3} \mathrm{~dB}$ \\
Bandwidth & $b w=36 \times 10^{6} \mathrm{~Hz}$ \\
Boltzmann constant & $k_{b o l t}=-228.6$ \\
\hline & $L_{a t m}=0.35$ \\
\hline Atmospheric loss & \\
\hline &
\end{tabular}

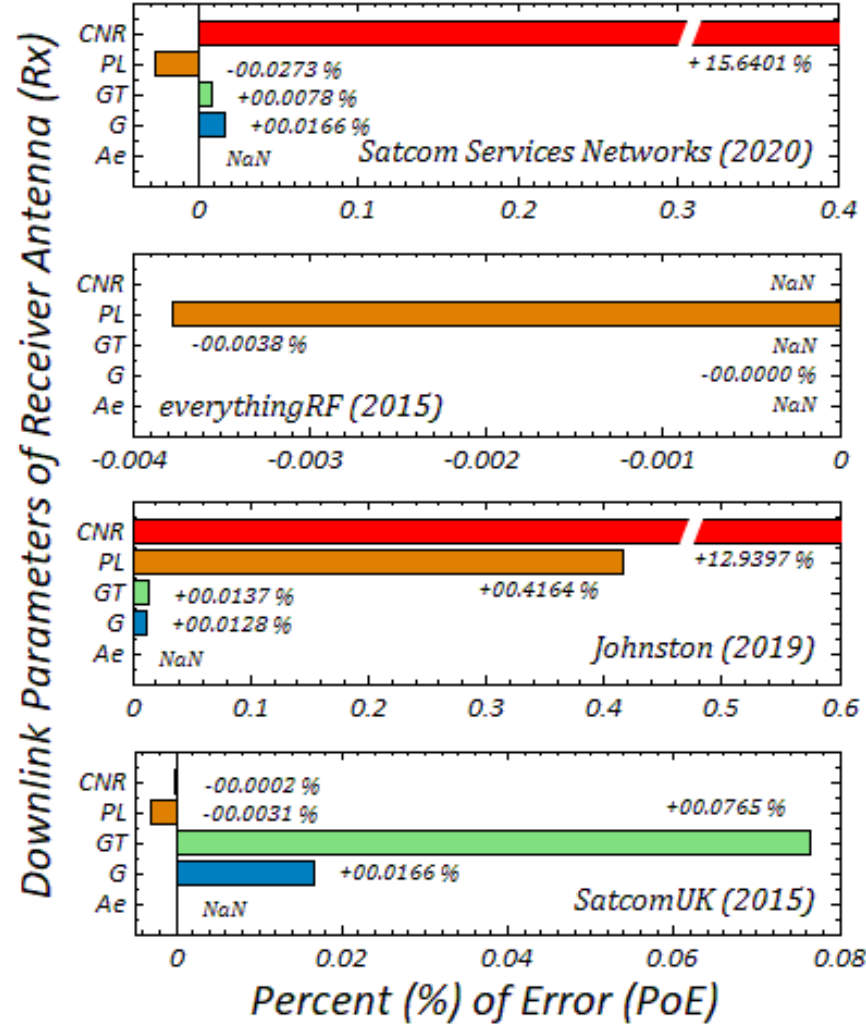

Figure 19: Percent (\%) of Error (PoE) of Downlink parameters calculated based on various web tools comparing with the proposed X-Band Link-budget tool

\section{CONCLUSIONS}

This study presents the design of a Link Budget web application tool for Military X-band satellite communication. Theoretical study on Link Budget analysis is conducted from six points of views such as transmitter antenna ( $T x)$; satellite; receiver antenna $(R x)$; azimuth $(\alpha)$, elevation $(\vartheta)$, and topocentric distance $(d)$ analysis for $T x \& R x$; and rain attenuation. Azimuth angle, elevation angle, and distance analysis are carried out based on the theory of spherical geometry. Based on the theoretical study, all input and output parameters were tabulated in designing the X-Band Link Budget web-application tool. The prototype is developed based on HTML, PHP, Javascript, and MySQL so that the tool can be used through the internet by any portable device and can store user and usage information based on the necessity of past history analysis. The designed web tool presents novel concepts in terms of user interfaces, user types, database, and usage statistics. Implementation of the peer-user concept could be considered as one of the interesting points which will enhance one step forward in the design Link Budget tool. Several security issues are considered in designing the proposed web tool. The manuscript also presents a comparative study among various tools available on the Internet and proposed X-Band web tool. Comparative results show little PoEs among various output parameters of designed X-Band Link Budget tool and other web tools which reflect the reliability and viability of the proposed system for practical use.

The system can be improved by developing apps for some specific mobile devices used in Military activities. Outcomes of this study will be more effective if this can be implemented in intelligent Earth Station control, Military vehicles in hazardous area, and Robots or autonomous systems for satellite communication. 


\section{ACKNOWLEDGEMENTS}

The authors would like to express their gratitude to the Ministry of Education Bangladesh. They also would like to present their appreciations to the R\&D (Robotics) Section at DREAM Robotics Ltd. and the departments of CSE at three highly regarded institutions, BAUST, DIU, and MIST, in Bangladesh.

\section{REFERENCES}

Abdullah, A. I., Ismail, A. F., Badron, K., \& Hashim, W. (2018). Fade Margin Estimations for Malaysian Armed Forces Military X-Band Satellite Communication Links. International Journal of Future Generation Communication and Networking, 11(3), 1-10.

Adhikari, A., Das, S., Bhattacharya, A., \& Maitra, A. (2011). Improving Rain Attenuation Estimation: Mod-Elling of Effective Path Length Using Ku-Band Measurements at A Tropical Location. Progress in Electromagnetics Research B, 34, 173-186

Al-Dalowi, A.H., Khoshnaw, A.I., \& QasMarrogy, G.A. (2017, March 29-30). Satellite Link Budget Calculator by Using $M A T L A B / G U I . \quad 1^{\text {st }}$ International Conference of Cihan University-Erbil on Communication Engineering and Computer Science (CIC-COCOS'17), Cihan University-Erbil, Kurdistan Region-Iraq, 74-78.

Al-Saegh, A. M., Sali, A., Mandeep, J. S., Ismail, A., Al-Jumaily, A. H. J., \& Gomes, C. (2014). Atmospheric Propagation Model for Satellite Communications. In Bennett, K. (Eds.), MATLAB Applications for the Practical Engineer, Chapter: 9, INTECH, (pp. 249-275), DOI: 10.5772/58238.

Bazzi, A., Giorgetti, A., Pasolini, G., \& Schena, V. (2005). Gap Fillers for Railway Tunnels: Technologies and Performance. EMC Europe Workshop, Rome, Italy, 147-150.

Cakaj, S., Keim, W., \& Malarić, K., (2007, May 30 - June 1). Communications Duration with Low Earth Orbiting Satellites. Proceedings of the Fourth IASTED International Conference on Antennas, Radar, and Wave Propagation, Montreal, Quebec, Canada, (pp. 85-88).

Capela, C. J. R. (2012). Protocol of Communications for Vorsat Satellite (Link Budget) [Master Thesis, Master Degree in Electrical Engineering]. Faculdade de Engenharia, Universidade do Porto.

Cole, C. E. (2010). Missile Communication Links. Johns Hopkins APL Technical Digest, 28(4), 324-330.

Cross, D. (2020). Azimuth/Distance calculator. Extracted on 18th Apr. 2020. Source: http://cosinekitty.com/compass.html

CS (2016). The Link Budget and Fade Margin: Application Note. Campbell Scientific Inc., Copyright 2016. App. Note Code: 3RF-F.

Elechi, P., \& Otasowie, P. O. (2016). Comparison of Empirical Path Loss Propagation Models with Building Penetration Path Loss Model. International Journal on Communications Antenna and Propagation (I.Re.C.A.P.), 6(2), 116-123. DOI: 10.15866/irecap.v6i2.8013

Elbert, B. R. (2004). The Satellite Communication Applications Handbook (Second Edition). Chapter 12: Frequency Coordination and Regulation of Services. Artech House, Inc., 685 Canton Street, Norwood, MA 02062, (pp. 445-482).

everithingRF (2015). RF Calculators. Extracted on 20th Apr. 2020. Source: https://www.everythingrf.com/rf-calculators

Fadilah, N., \& Pratama, R. (2018). Comparison of rain attenuation estimation in high frequency in Indonesia region for LAPAN communication satellite. $6^{\text {th }}$ International Seminar of Aerospace Science and Technology, IOP Conf. Series: Journal of Physics: Conf. Series 1130 (2018) 012036, IOP Publishing, (pp. 1-7), DOI: 10.1088/1742-6596/1130/1/012036

Geyer, M. (2016). Earth-referenced Aircraft Navigation and Surveillance Analysis, Project Memorandum - June 2016, DOT-VNTSC-FAA-16-12, Prepared for: Federal Aviation Administration Wake Turbulence Research Office, U.S.
Department of Transportation Research and Innovative Technology Administration, John A. Volpe Transportation Systems Center, (pp. 2.1-2.13).

Griffiths, H., Cohen, L., Watts, S., Mokole, E., Baker, C., Wicks, M., \& Blunt, S. (2015, January). Radar Spectrum Engineering and Management: Technical and Regulatory Issues. Proceedings of the IEEE, 103(1), 85-102, DOI: 10.1109/JPROC.2014.2365517

Hyde, G., \& Bargellini, P. L. (2002). Satellite and Space Communications. In Middleton, W. M., \& Valkenburg, M. E. V. (Eds.), Reference Data for Engineers: Radio, Electronics, Computer, and Communications, $9^{\text {th }}$ Edition, Elsevier Inc. (pp. $27.11-27.12)$.

Hossain, M. S. \& Islam, M. A. (2017, February 16-18). Estimation of Rain Attenuation at EHF bands for Earth-to-Satellite Links in Bangladesh. International Conference on Electrical, Computer and Communication Engineering (ECCE), Cox's Bazar, Bangladesh (pp. 589-593).

Ippolito L. J. (1986). Chapter 5: Rain Attenuation Prediction Methods. In Radiowave Propagation in Satellite Communications. Springer, Dordrecht, DOI: https://doi.org/10.1007/978-94-011-7027-7_5

Ismail, A. F., Zhiger, S., Hasan, M. K., \& Hashim, W. (2017). An Intuitive Link Budget Tool for Military Satellite Communication. International Journal of Software Engineering and Its Applications, NADIA, 11(2), 97-106.

ITU (2011). Handbook, Earth Exploration-Satellite Service. English Edition 2011, Recommendation Bureau, ITU.

ITU-R (2003a). Propagation data and prediction methods required for the design of Earth-space telecommunication systems, (Question ITU-R 206/3), RECOMMENDATION ITU-R P.618-8, Rec. ITU-R P.618-8.

ITU-R (2003b). Specific attenuation model for rain for use in prediction methods, (Question ITU-R 201/3), RECOMMENDATION ITU-R P.838-2, Rec. ITU-R P.838-2.

ITU-R (2005). Specific attenuation model for rain for use in prediction methods, (Question ITU-R 201/3), RECOMMENDATION ITU-R P.838-3, Rec. ITU-R P.838-3.

Johnston, E. (2019). Satellite Link Budget Calculator. Satellite Signals Limited. Extracted on 24th Apr. 2020. Source: https://www.satsig.net/linkbugt.htm

Kanellopoulos, J. D., Panagopoulos, A. D., \& Livieratos, S. N. (2000). Differential Rain Attenuation Statistics Including an Accurate Estimation of the Effective Slant Path Lengths. Progress in Electromagnetics Research, PIER 28, 97-120, DOI: 10.2528/PIER99060503

Karim, S. M. R., Sakib, S., Islam, M. T., \& Ahamed, F. A. S. (2018). A Review of Communications Satellite by Focusing on 'Bangabandhu Satellite-1', the First GEO Communications Satellite of Bangladesh. International Journal of Networks and Communications, $8(5), \quad 123-128, \quad$ DOI: 10.5923/j.ijnc.20180805.01

Kestwal, M. C., Joshi, S., \& Garia, L. S. (2014). Prediction of Rain Attenuation and Impact of Rain in Wave Propagation at Microwave Frequency for Tropical Region (Uttarakhand, India). International Journal of Microwave Science and Technology, Hindawi Publishing Corporation, 2014, 1-6, DOI: http://dx.doi.org/10.1155/2014/958498

KYMETA (2019). Link Budget Calculations for A Satellite Link with an Electronically Steerable Antenna Terminal. Kymeta Corporation and its affiliates.

Lwas, A. K., Islam, M. R., Habaebi, M. H., Mandeep, S. J., Ismail, A. F., Daoud, J. I., \& Zyoud, A. (2015). A Modified Effective Path Length for Predicting Rain Attenuation Based on Measurements in Penang-Malaysia. ARPN Journal of Engineering and Applied Sciences, 10(21), 10096-10100.

Mahmud, M. R. A., \& Khan, Z. S. (2009, September). Analysis and Planning Microwave Link to Established Efficient Wireless Communications [Master thesis, Master of Science in Electrical Engineering]. Department of Signal Processing, School of Engineering, Blekinge Institute of Technology. 
Mantoro, T., Akhtaruzzaman, M., Mahmud, M., \& Ayu, M. A. (2015). Design and Development of an Interactive Monitoring System for Pilgrims in Congregation of Hajj Ritual. Journal of Convergence Information Technology (JCIT), 10(1), 28-57.

Mebrek, M. A., Abderrahmane, L. H., Himeur, A., \& Bendoukha, S. (2012). Configuration and the Calculation of Link Budget for a Connection via a Geostationary Satellite for Multimedia Application in the $\mathrm{Ka}$ band. International Journal of Electronics and Communication Engineering, World Academy of Science, Engineering and Technology, 6(4), 466470.

Medvedev, P. A., Bykov, L. V., Bykov, V. L., Novorodskaya, M. V., \& Sherstneva, S. I. (2018). Methods for Transformation of Rectangular Spatial Coordinates to Geodetic Coordinates. International Journal of Engineering \& Technology (IJET), 7(4.38), 1179-1186

Mello, L. d. S., \& Pontes, M. S. (2012). Unified Method for the Prediction of Rain Attenuation in Satellite and Terrestrial Links. Journal of Microwaves, Optoelectronics and Electromagnetic Applications, 11(1), 1-14.

Mir, H., Cui, X., Shahzad, A., \& Jumani, R, (2018). Optimization of Satellite Link to Earth Station Using Satellite Tool Kit (STK). International Journal of Electrical, Electronics and Data Communication, 6(12), 48-52.

Nizam, S. J. (2008, April 19). Military Application of Satellite. The Daily Star, Bangladesh.

Nuroddin, A. C. M., Ismail, A. F., Abdullah, K., Badron, K., Ismail, M., \& Hashim, W. (2013). Rain Fade Estimations for the XBand Satellite Communication Link in the Tropics. International Journal of Computer and Communication Engineering, 2(4), 408-412, DOI: 10.7763/IJCCE.2013.V2.215

OMNI (2020). Omni Calculator: Azimuth calculator. Extracted on 18th Apr. $2020 . \quad$ Source: https://www.omnicalculator.com/other

Panchal, P., \& Joshi, R. (2016). Performance Analysis and Simulation of Rain Attenuation Models at $12-40 \mathrm{GHz}$ Band for an Earth Space Path over Indian Cities. Procedia Computer Science, ELSEVIER, 79(2016), 801-808.

Panou, G., Korakitis, R., \& Delikaraoglou, D. (2018). Cartesian to Geodetic Coordinates Conversion by an Iterative Geometrical Method. Quod Erat Demonstrandum - In quest of the ultimate geodetic insight, Special issue for Professor Emeritus Athanasios Dermanis, School of Rural and Surveying Engineering, AUTh, 274-281.

RACOM (2018). Application Notes, RACOM Radio Dato Networks, Version 1.0, 7/12/2018, 1-17.

Ranjan, A., Panigrahi, B., Rath, H. K., Misra, P., Simha, A., \& Sahu, H. B. (2018, February). A Study on Pathloss Model for UAV Based Urban Disaster and Emergency Communication Systems. IEEE Twenty Fourth National Conference on Communications (NCC), Hyderabad, India. DOI: 10.1109/NCC.2018.8600260

Roddy, D. (2006). The Geostationary Orbit (Chapter 3). In Satellite Communications, $4^{\text {th }}$ Edition, McGraw-Hill, (pp. 77-101).

SatcomUK (2015). Satellite Link Budget Calculators. Extracted on 24th Apr. 2020. Source: http://www.satcoms.org.uk/satellitelink-budget-calculator.asp

Satcom Services Networks (2020). Link Budget Calculations: Geostationary Satellite Azimuth and Elevation Calculation. Extracted on 18th Apr. 2020. Source: https://satcomservices.com/VSAT/linkbudget.html
Shrestha, S., \& Choi, D. Y. (2017). Characterization of Rain Specific Attenuation and Frequency Scaling Method for Satellite Communication in South Korea. International Journal of Antennas and Propagation, Hindawi, 2017, 1-16, DOI: https://doi.org/10.1155/2017/8694748

Shrestha, S., \& Choi, D. Y. (2019). Rain Attenuation Study at KuBand over Earth-Space Path in South Korea. Advances in Astronomy, Hindawi, 2019, 1-12, DOI: https://doi.org/10.1155/2019/9538061

Soler, T. (1976). On differential transformations between Cartesian and curvilinear (geodetic) coordinates. Rep. No. 236, Dept. of Geodetic Sci., Ohio State Univ., Columbus, Ohio.

Soler, T., \& Eisemann, D. W. (1994). Determination of Look Angles to Geostationary Communication Satellites. Journal of Surveying Engineering, 120(3), 115-127.

Song, H., \& Schnieder, E. (2019). Development and Evaluation procedure of the Train-centric Communication based System. IEEE Transactions on Vehicular Technology, 68(3), 20352043, DOI: 10.1109/TVT.2018.2868881

Stutzman, W. L. (1998). Estimating Directivity and Gain of Antennas. IEEE Antennas and Propagation Magazine, 40(4), $7-11$

SWA (2020). South West Antennas, RF Calculators and Conversion Tools. Extracted on 18th Apr. 2020. Source: https://www.southwestantennas.com/rf-calculators-andconversion-tools

TRANZEO (2010). Wireless Link Budget Analysis: How to Calculate Link Budget for Your Wireless Network. Tranzeo Wireless Technologies Inc., TR3014-01, 1-4, http://www.tranzeo.com/allowed/Tranzeo_Link_Budget_Whit epaper.pdf

TRIAXMAN (2020). SatLex: Calculator for azimuth and elevation angle. Extracted on 20th Apr. 2020. Source: https://satlex.de/en/azel_calcparams.html?satlo $=7.0 \&$ user_satlo $=7 \&$ user_satlo_dir $=E \&$ loca tion $=\& l a=41 \& l o=29 \&$ country_code $=$ ng $\&$ diam_w=70\&diam $\mathrm{h}=75$

TutorialsWeb (2020). A home for Tutorials; Satellite Look Angle Calculator: Azimuth and Elevation Angles Calculator. Extracted on 19th Apr. 2020. Source: https://www.tutorialsweb.com/satcom/calculation-of-satellitelook-angles.htm

Wangn, Y., Huynh, G., \& Williamson, C. (2013). Integration of Google Maps/Earth with microscale meteorology modelsand data visualization. Computers \& Geosciences, 61(2013), 2331

Ya'acob, N., Tajudin, N., Sarnin, S. S., Rahim, S. A. E. A., \& Manut, A. (2018). Link Budget and Noise Calculator for Satellite Communication. IOP Conf. Series: Journal of Physics: Conf. Series 1152 (2019) 012021, 1-7, DOI:10.1088/1742-6596/1152/1/012021

Yulianto, F. (2012). Link Budget Calculator Software Design with Microsoft Visual Basic. Jurusan Sistem Informasi, Sekolah Tinggi Manajemen Informatika Dan Komputer, Amikom Yogyakarta.

Yussuff, A. I. O., \& Khamis, N. H. H. (2013). Modified ITU-R Rain Attenuation Prediction Model for a Tropical Station. Journal of Industrial and Intelligent Information, Engineering and Technology Publishing, 1(3), 155-159, DOI: 10.12720/jiii.1.3.155-159

Zhiger, S. (2017). Development of an Intuitive Link Budget Tool for Military Satellite Communications [Master of Science thesis, IIUM]. International Islamic University Malaysia. 